\title{
Learning from failure: Damage and Failure of Masonry Structures, after the 2017 Lesvos Earthquake (Greece)
}

\author{
Georgios Vlachakis ${ }^{1 *}$, Evangelia Vlachaki ${ }^{2}$, Paulo B. Lourenço ${ }^{1}$
}

${ }^{1}$ ISISE, Department of Civil Engineering, University of Minho, Guimarães, Portugal

${ }^{2}$ Independent researcher, Voreiou Ipeirou 9, 26500 Patras, Greece

${ }^{*}$ Correspondence to: Georgios Vlachakis, ISISE, Department of Civil Engineering, University of Minho, Campus de Azurém, Guimarães, 4800-058, Portugal; E-mail: giorgovlachaki@gmail.com

Abstract - On the $12^{\text {th }}$ of June 2017 an earthquake of Mw=6.3 struck SSE of Lesvos Island, causing one human fatality and severe damage to the built environment. The traditional settlement of Vrissa was the most affected area, having masonry structures as the majority of its building stock. The objective of the present study is two-fold: to present the structural damage and failure patterns induced by the Lesvos earthquake to masonry structures; to highlight the causes and weaknesses that led to damage, or the factors that prevented it. Particular attention is paid to traditional construction techniques and architectural features that contributed to the seismic response of the structures, either having beneficial or detrimental effect. To this end, a field reconnaissance has been conducted and meaningful technical conclusions are drawn by the observations. Structural systems of both unreinforced and timber-reinforced masonry are inspected. Besides the identification of frequent cases of local, out-of-plane and in-plane mechanisms, combined global mechanisms are also pointed out. Finally, insight of the performance of past interventions is also given, assisting the challenging task of engineering practice.

Keywords: Seismic damage; Post-earthquake survey; Strengthening interventions; Performance; Traditional buildings

\section{Introduction}

On the $12^{\text {th }}$ of June 2017 , at $12: 28 \mathrm{GMT}$, a shallow earthquake with magnitude $M w=6.3$ struck SSE of Lesvos Island [1]. The epicenter of the seismic event, according to National Observatory of Athens (NOA) [2], had Latitude $38.84^{\circ} \mathrm{N}$ and Longitude $26.36^{\circ} \mathrm{E}$, being approximately $15 \mathrm{~km}$ offshore of Lesvos island and with a depth of around $10 \mathrm{~km}$. The seismic signal of the ground motion was instrumentally recorded only at distances of around $35 \mathrm{~km}$ at Mytilene in Lesvos island, and at Karaburun in Turkey, being both outside of the area of maximum damage [3]. The former station recorded PGA values of 0.024/0.070/0.044 [g] while the later $0.051 / 0.043 / 0.036$ [g] for the NS, EW and vertical components, respectively. Subsequent studies estimated that the southern coast of Lesvos experienced PGAs of about 0.2 [g] [3] [4], or PGVs of about $0.3 \mathrm{~m} / \mathrm{s}$ [5]. Figure 1 present the existing shakemaps available online by NOA [2]. It is understood that shakemaps provide only 


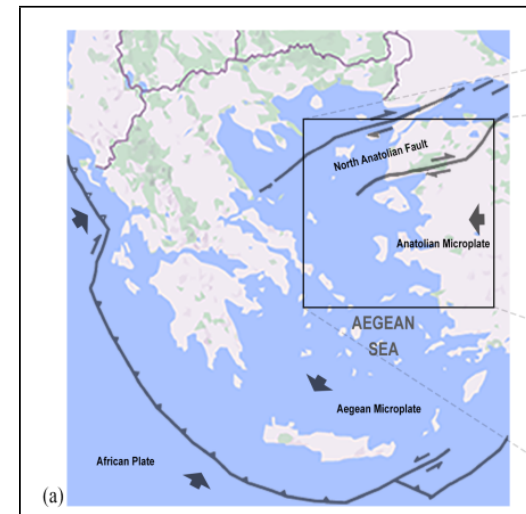
GMT.

approximate estimations of the seismic severity, as ground motion attenuation relations are employed. Moreover, it should be noted that the currently in-force Greek seismic code provides a PGA of 0.24 [g] for a return period of 475 years in the island, while more recent studies proposed even higher values [6]. The main seismic event was followed by over 500 aftershocks in the subsequent four months [7], all concentrated in an area of about 30x10 $\mathrm{km}^{2}$ [4], expanding NW-SE of the mainshock's epicenter. Among these, 31 events had a magnitude greater than $3.5 \mathrm{Mw}$, with the largest one being 5.3 , on the $17^{\text {th }}$ of June at 17:50

Figure 1. (a) Main lithospheric plates of Greece (modified from [8]). Shakemaps in terms of (b) PGA (in \% g) and (c) PGV (in cm/s). Obtained from [2]. Island of Lesvos is highlighted with red contour and the epicenter indicated with a star.

From a seismotectonic point of view, the 2017 Lesvos earthquake occurred at a seismically active region of the Aegean Region. The Aegean microplate is bounded by the Hellenic Trench to the south and by the western extension of the North Anatolian Fault to the north [1]. The northeastern Aegean is subjected to NE-SW dextral shearing transfer by the North Anatolian Fault and stretching due to slab rollback and gravitational spreading of the Aegean lithosphere [5]. More specifically, the Lesvos Island lies at the transition regime of the normal faulting of the western Anatolia and the strike-slip faulting in the Aegean. Three main fault systems have been recognized in the island [1], and the 2017 Lesvos earthquake mainshock and aftershocks ruptured the eastern segment of the Lesvos Basin fault [5]. The seismic sequence was associated with both normal and strike-slip faulting, along a NW-SE trending plane. More importantly, [1,5,7] among others, pointed out that the rupture propagated unilaterally to NW towards the south coast of Lesvos, where the most severe damage to the built environment was observed. This forward directivity characteristic appeared to have imposed near-fault effects to an area that has a relatively large distance from the epicenter, yet is just above the asperity with the major slip [5]. For more in-depth details of the seismological characteristics of the event, the reader is referred to $[1,4,5,7,9]$.

In the same day, right after the seismic event, the Greek state emergency mechanism was mobilized and visited the island. More specifically, the Minister of Public Order, the Secretary-General of Civil Protection, the Secretary-General of Infrastructures, the President of Earthquake Planning and Protection Organization, directors of the Secretary-General of Civil Protection and of Earthquake Rehabilitation Organization (ERO), and members of the 68 Special Unit for Disaster Mitigation were taken to the island by helicopters. The Lesvos 
earthquake caused one human fatality and fifteen people were injured. Severe damage was caused to the built environment, while all afflicted residents were relocated to temporary housing. In the day after the earthquake, engineers of the ERO, assisted by local engineers, started the first level of buildings' inspections (completed on the $25^{\text {th }}$ of June). During this process, 1.776 constructions were inspected, among which 937 were found as immediately uninhabitable. The second level of inspections followed between the $26^{\text {th }}$ of June to the $28^{\text {th }}$ of July, during which 1.650 constructions were inspected. Among them, 319 were tagged as "unsafe for use", 867 as "temporary usage is not permitted" and 464 as "immediately usable". The spatial distribution of the damaged constructions was concentrated at the southwestern part of the island being mainly old masonry buildings, while some minor damage was also reported in Mytilene, in Chios Island and at the facing coasts of Turkey (Figure 2(a)). In fact, about $50 \%$ of the totally reported damaged constructions and 290 out of the 319 severed damaged cases were reported in the traditional settlement of Vrissa. It appeared that about $80 \%$ of the Vrissa's building stock was damaged (Figure $2($ b)), becoming the "epicenter" of the earthquake's destruction, with an estimated EMS-98 [10] macroseismic intensity of IX [1]. Regarding the environmental effects, slope movements were induced in some areas [3,4]; while a non-damaging tsunami of about $35 \mathrm{~cm}$ peak-topeak amplitude was reported at the Plomari port [11].

The fact that Vrissa settlement suffered by far most of the induced seismic damage caught the attention of the scientific community [12]. Actually, it was reported as an "impact paradox" due to the following two unexpected facts: 1) the settlement lies further inland from the epicenter than other settlements with less damage (Figure 2(a)), and 2) the northwestern part of the settlement concentrated the majority of the damage (Figure 2(b)), despite having a uniform building stock. The available studies pointed out as the decisive factors a synergy of seismic directivity and near fault effects, the geological alluvial deposits of the northern part of the settlement, the presence of geotechnical unstable zones and the vulnerable masonry constructions. More specifically, [5] highlighted that Vrissa is located at a very short distance from the western edge of the fault and the slip patch at the same time, while forward directivity was developed towards the settlement. Some structural observations about the seismic motion directivity are provided in the Appendix. $[3-5,12,13]$ underlined that the northern part of the settlement lies over recent Holocene alluvial deposits that amplified significantly the seismic motion (Figure 2(b)). $[4,12]$ indicated that the steep slopes of the western part of the settlement showed to be unstable and even generating local landslides. The aforementioned remarks provide some justification of the localization of damage in the Vrissa settlement, when compared to the surrounding area. Nevertheless, the studies available in literature paid little attention to the structural aspects of the building stock, as they were mainly limited to large-scale observations. 


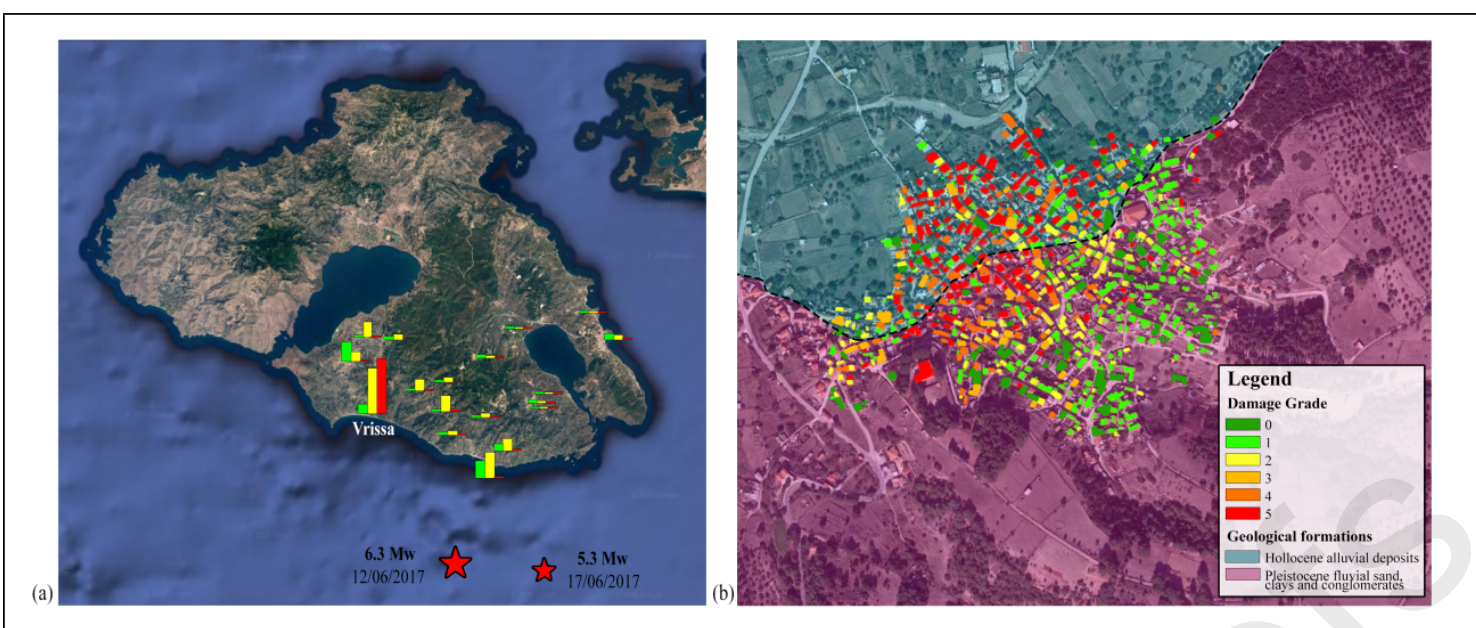

Figure 2. (a) Geographical distribution of damaged constructions over the island of Lesvos (information provided by ERO and correspond to the tags of the second level of inspections). (b) Damage distribution in the village of Vrissa, based on the damage grades after [12]; and geological formations of the area, after [14].

The objective of the present study is two-fold: to present the structural damage and failure patterns induced by the Lesvos earthquake to masonry structures; to highlight the causes and weaknesses that led to damage, or factors that prevented it. Throughout the process, particular attention is paid to traditional construction techniques and architectural features that contributed to the seismic response of those structures, either having beneficial or detrimental effect. Moreover, as earthquake engineering knowledge on masonry structures has been evolving rapidly over the last decades, actual seismic events provide a unique opportunity to learn from the response of real historical masonry constructions over a large scale (e.g.:[14-35]). Finally, an insight of the performance of past interventions is attempted, thus assisting the challenging task of engineering practice [37].

To this end, a field reconnaissance has been conducted by the first author at the area struck by the Lesvos earthquake. Given the safety concerns or limited access to private property, the majority of the buildings have been inspected from outside, with the inherent limitations. Moreover, almost no conclusions could be derived by completely collapsed buildings, restricting further the field reconnaissance. Nevertheless, observations and comments are accompanied by representative photos, while simplified sketches are provided in order to facilitate the interpretation and systematize the observations. All examples shown correspond to the settlement of Vrissa, unless otherwise stated, as this settlement witnessed most of the induced seismic damage for this event, as explained earlier.

The outline of the paper is as follows: Section 2 presents the construction typologies inspected, referring to the materials and the techniques used; Section 3 illustrates and classifies the observed damage and failure patterns; Section 4 reports about the performance of past interventions that have been recorded; and, finally, the conclusions of the study are summarized in Section 5 . 
131

132

133

134

135

136

137

138

139

140

141

142

143

144

145

146

147

148

149

150

151

152

153

154

155

156

157

158

159

160

161

162

163

164

165

\section{Construction Typologies}

The historical building stock of the settlement of Vrissa consists mainly of stone masonry constructions, and less frequently of brick masonry constructions. The majority of these were built at the second half of the $19^{\text {th }}$ century and the beginning of the $20^{\text {th }}$ century, as a reconstruction process after a destructive earthquake that hit the area in 1845 [38] (pp. 659660). The residential buildings in most cases follow a rectangular in plan layout of about $4 x$ $10 \mathrm{~m}$, and the height is up to 3 stories. The majority of the roofing and flooring systems are made of timber, while the internal spaces are separated by internal walls, poorly connected to the masonry façades. Timber-reinforced masonry buildings were also identified, composing a small yet particular structural typology.

The following paragraphs provide an overview of the construction materials and techniques that were identified in these constructions, highlighting structural aspects that played a decisive role in the buildings' seismic response.

\subsection{Construction Materials}

In general, materials of poor quality were used in the masonry construction, resulting in remarkably low seismic performance. Despite the good quality of ignimbrite stones extracted at quarries in the surrounding area and the local brick manufactories, many of the structural walls in the Vrissa settlement were built of relatively small river-side stones (i.e. dimension smaller than $0.20 \mathrm{~m}$ ), due to their abundant presence nearby and the ease of collection. The smooth and round surface of such stones did not allow significant bond and interlocking to be developed and structural walls disintegrated easily (Figure 3). Earth mortar was mainly used in the masonry buildings, introducing further vulnerability. Such mortar is characterized by low cohesive properties, low compressive strength and sensitivity to water content (Figure 3). Lime and cement based mortars were also employed, but only rarely, usually as subsequent repointing applications. A detailed investigation of the mortar, as performed locally after the 2016 Central Italy [39] or after the 2010-2011 Christchurch earthquakes [27], could provide a better insight of its characteristics and its role within the masonry assemblage.

Material degradation contributed in worsening the performance of both masonry and timber elements. The abandonment that the Greek countryside experienced in the last decades resulted in substandard or lack of maintenance. Water ingress deteriorated both the mortar and the timber elements.

Masonry built with rougher units or bricks was able to develop a more homogenized and better response. 
(a)

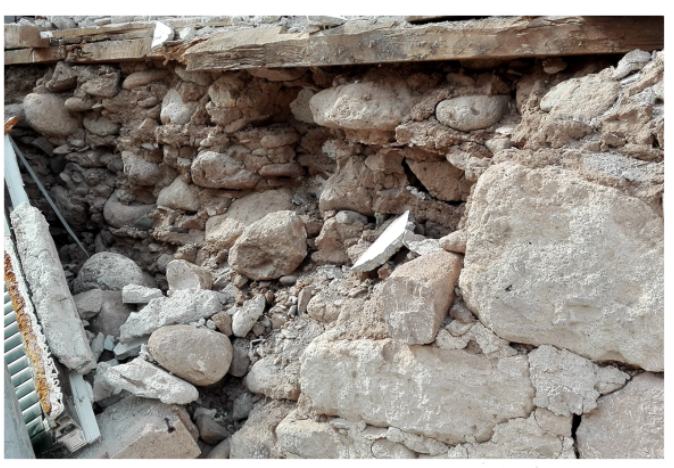

(b)

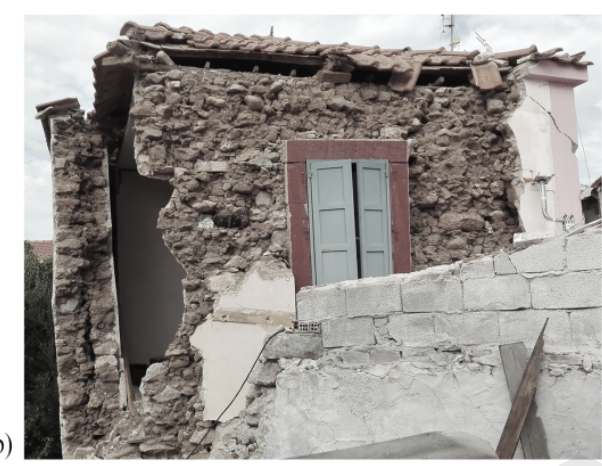

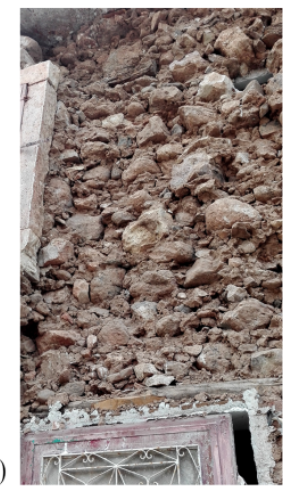

(d)
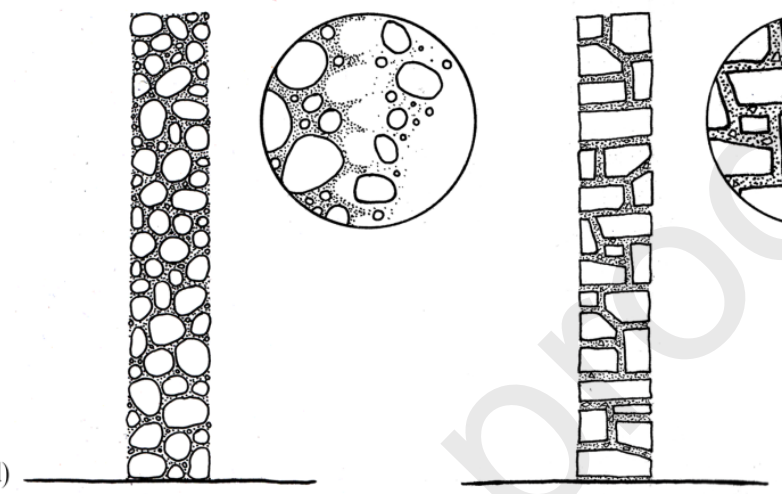

Figure 3. (a)-(c): Poor masonry constituents that resulted in masonry disintegration. (d) Schematic sketch of vulnerability induced by smooth stone surface, round stones and earth mortar with lack of adhesive properties.

\subsection{Construction Techniques}

\subsubsection{Unreinforced Masonry}

UnReinforced Masonry (URM) buildings were constructed typically with two and three-leaf masonry walls with a thickness varying between 0.4 and $0.7 \mathrm{~m}$. However, the lack of transversal interlocking stones (through stones, bond stones, tie stones or diatonoi) that could connect the external leaves, resulted in detachment and masonry delamination (Figure 3 (b), (c), Figure 4 (a), (b), (d)). This construction deficiency appeared to be crucial for the seismic response of the URM buildings, as it triggered or assisted many structural failures, as shown below.

175 In some structures built at the central part of the settlement, a different kind of building material was used between the parallel leaves. Perfectly cut stones were employed for the outer leaf of the façade in order to demonstrate wealth and solidity, while rubble stones were used for the rest of the section (Figure 4 (c), (d)). Once again, no mechanical connection between the leaves was ensured, while the different stiffness of the masonry across the section increased its vulnerability. 


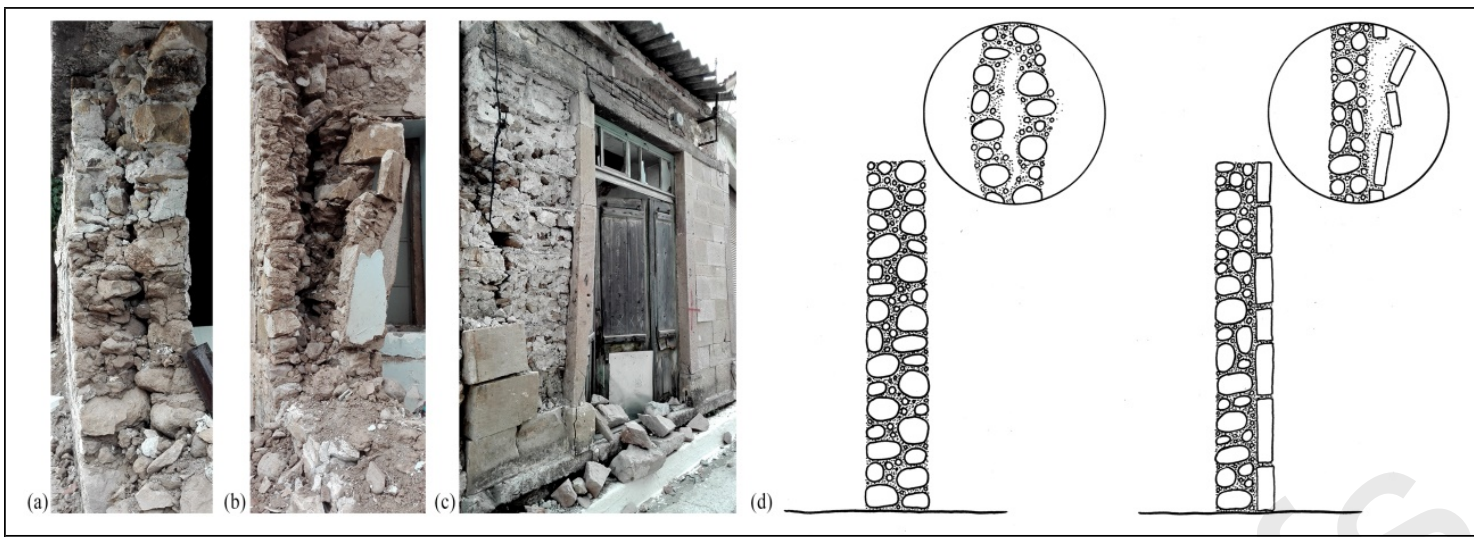

Figure 4. (a)-(b) Typical multi-leaves wall sections with lack of transversal interlocking stones. (c) Street façade with different material of wythes across the thickness. (d) Schematic sketch of cases (a)-(b):left, and (c): right and their failure pattern.

181

The corners of URM buildings were usually constructed with quoin-stones. Well-shaped and in most cases, being made with more than a single stone in the course, quoins helped the connection of transversal walls, preventing local or global failures (Figure 5 (a), (b), (d)), as shown below. Still, quoins were often insufficient to prevent the development of corner cracks, especially when an additional set of ashlar stones was poorly constructed or missing (Figure 5 (c)). The use of ashlar stones was also adopted for the stones in the frames around building openings. Often, monolithic squared stones were used for posts and lintels around the openings, as a local architectural feature. The lack of proper interlocking of these elements with the rest of the masonry, leads to the assumption that these are decorative, non-structural elements.

Tie rods, commonly used in the Mediterranean region, were observed on just three buildings of the settlement (Figure 9 (c)). Despite the fact that the benefits of this technique (see e.g. [40] and references therein) were well understood in the past, its extended use was probably hampered in the area due to the difficulty in finding metal ties on the island and socioeconomic reasons.



Figure 5. (a)-(b) Adequate connection of quoin stones. Notice the presence of two stones per course. (c) Inadequate connection of quoin stones. Notice the lack of the set of ashlars in the corner and the fracture of one quoin stone at the bottom. (d) Schematic sketch of the role of quoin stones. 


\subsubsection{Timber-reinforced Masonry}

The use of timber elements has been recorded throughout the history of structural systems developed in Greece, for almost 5000 years, as a technique to improve the seismic response of structures. A chronological and regional overview of the vast variety of timber-reinforced masonry types can be found in [41]. Such structural solutions were observed also in the settlement of Vrissa, in the forms of: i) timber-laced masonry, and ii) timber-frame masonry.

Timber-laced masonry consists of timber ring beams placed at regular spacing across the height and as a pair across the thickness of the walls (Figure 6). Such a technique, as described in [41-44] and references therein, improves the seismic performance of the building in its inelastic range, by providing horizontal slip planes, dissipating energy and enhancing the masonry In-Plane (IP) and Out-Of-Plane (OOP) strength by confining portions of the walls. In addition, this technique enhances the connection between transversal walls and helps to tie the leaves of a wall together and avoid disintegration. During the reconnaissance campaign, the damage that was observed in timber-laced masonry structures was limited in-between the ring-beams across the height, demonstrating the adequacy of the system (Figure 6 (c)).

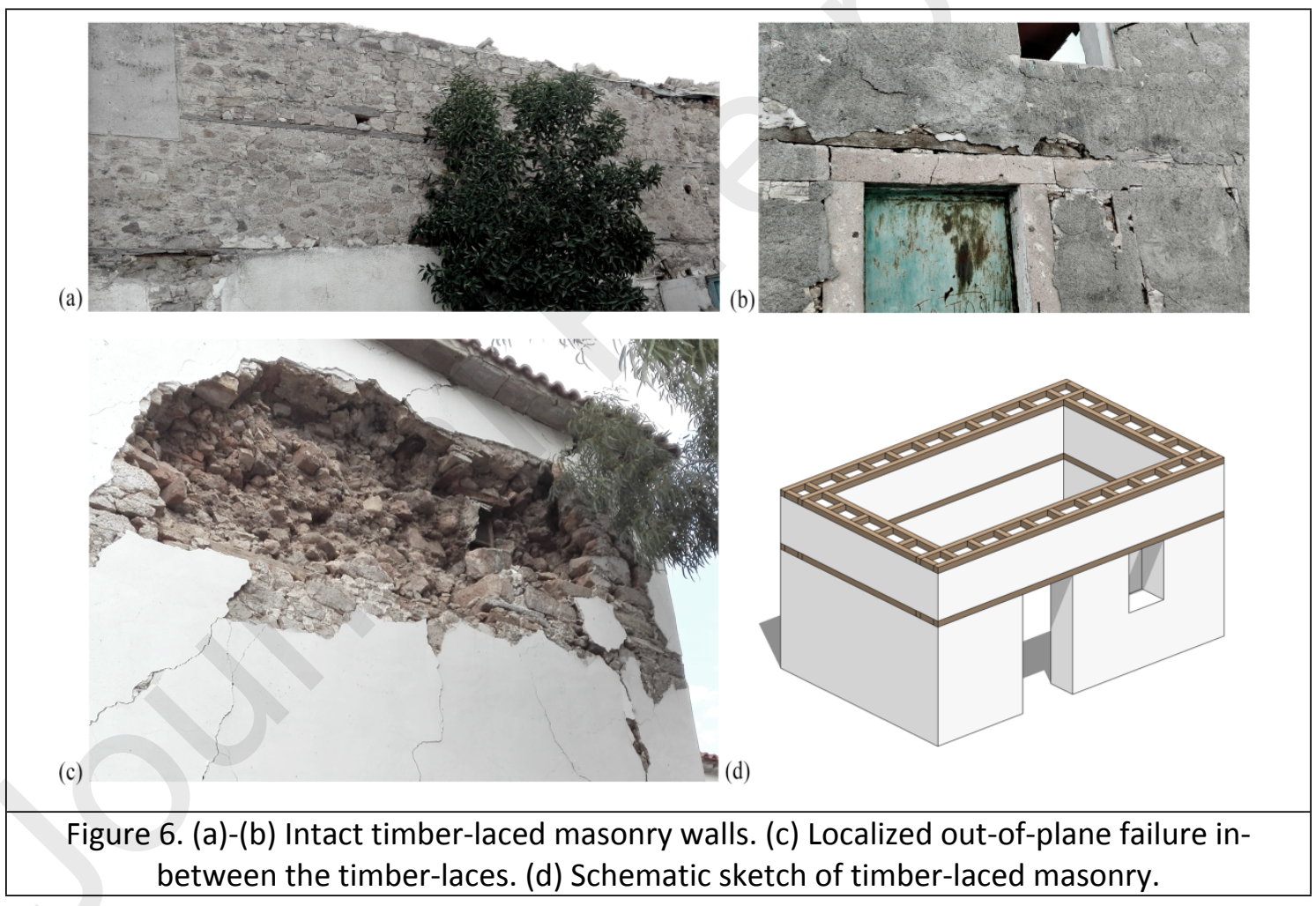

Timber-frame masonry (local name "friggia" [45]) consists of a composite structural system of a timber-frame with vertical posts, horizontal beams and diagonal bracing elements, together with masonry walls having one leaf as infill of the frame and the other as external cover of the frame (Figure 7). In most cases, the timber-frame system was observed to exist only on the upper floors, while resting on horizontal timber-laces at the crest of the masonry ground floor. In fact, the presence of the internal timber-frame seems to exclude the construction of timber-laces at the same areas. It appears that the two systems were not 
used complementary, but each one was considered sufficient by the local masons; a remark noted also by [46]. Moreover, special L-shaped corner elements were recognized at the timber connections in several buildings, providing increased stiffness and energy dissipation to the frame (Figure 7 (b), (d)). Similar structural systems in the world have been observed with a remarkably low vulnerability to earthquake actions; e.g. in $[23,46,47]$. During the field reconnaissance, only one total-collapse of such a structure was observed, probably due to other deficiencies that could not be recognized from the debris. More specifically, damage was mainly localized in the outer unreinforced leaf of the masonry walls resulting in OOP failures, while the timber-frame could stand the whole seismic event (Figure 7 (a), (b)). This structural redundancy prevented both inward collapses of the masonry walls and complete collapse of the roof system, thus protecting the buildings' inhabitants. Yet, one could argue that such OOP failures could have been prevented if the timber-frame was also confining the outer leaf with timber-laces at regular distances. Furthermore, it should be noted that the damage was much more extensive in cases with deficiencies, such as the irregular configuration of the braces, the lack of continuity of the timber-frame at the ground floor, the presence of poor connections or the level of degradation of the timber (Figure 7 (c)).

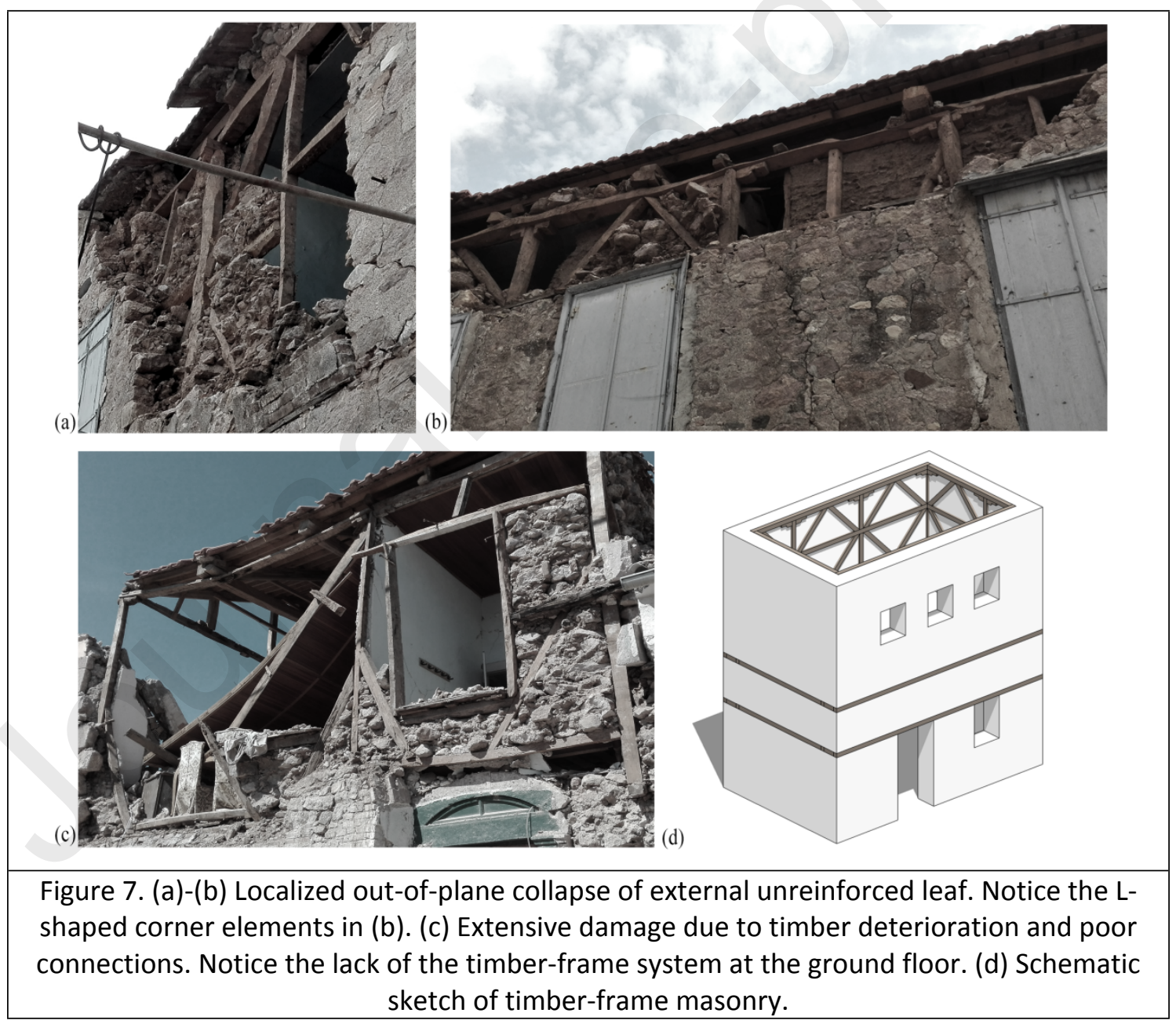




\section{Damage and Failure Patterns}

The earthquake-induced damage and failure patterns are described next, following a qualitative distinction of two limit states commonly used in earthquake engineering. In order to facilitate reading and to establish meaningful conclusions, the presentation is done according to a systematic classification of mechanisms. The description starts with local mechanisms, followed by the critical OOP mechanisms and the desirable IP mechanisms. Subsequently, three types of combined IP and OOP mechanisms are presented. Finally, the failure mechanisms of non-structural components are highlighted.

\subsection{Local Mechanisms}

Since masonry is non-homogeneous and non-monolithic, with negligible tensile strength and high mass, local failure mechanisms often occur prematurely during earthquake events. Whenever these local mechanisms are not prevented through proper construction details and structural connections; they may be activated even under small seismic input and lead to partial collapse, which provides very high structural vulnerability and a form of nonacceptable failure.

Disintegration of masonry can be considered a local mechanism in essence. In literature, it is also referred to as the "zero" mechanism [26], appearing when a masonry portion is unable to counteract almost any horizontal action and crumbles into pieces. Many cases of disintegration were identified during the reconnaissance, mainly as delamination of the external leaf (Figure 3, Figure 4 and Figure 8). The main factors that triggered such mechanisms are related to the low quality of the materials, the lack of interlocking stones of the different leaves or the lack of connection of the leaves with timber-laces.

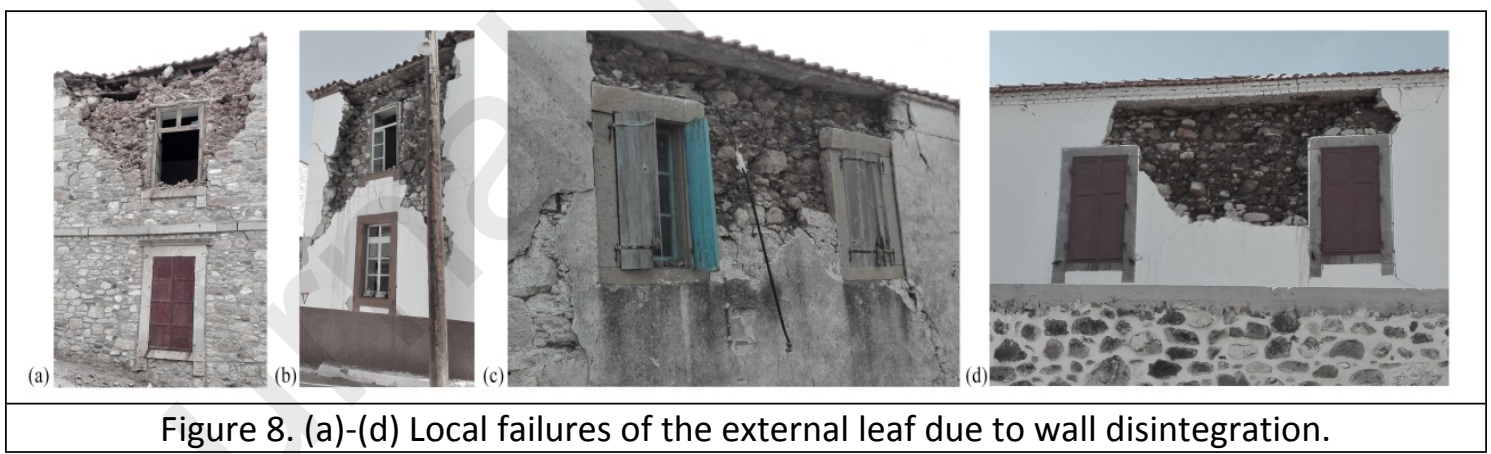

Overturning of gable end walls is a frequently occurring local mechanism. The notable vulnerability of this part of the constructions is attributed mainly to the inadequate connection with the roofing system and the lack of overburden weight (as the roof rafters are usually laid on the transversal walls), together with the amplified accelerations at the gable's height. Several collapses of gable walls were observed during the reconnaissance (Figure 9). Among them, it is worth to mention the gable wall collapse of the elementary school of Vasiliko, a settlement of around $7 \mathrm{~km}$ further inland from Vrissa which suffered almost no damage. This further highlights the vulnerability of the mechanism (Figure 9 (a)). 
(a)
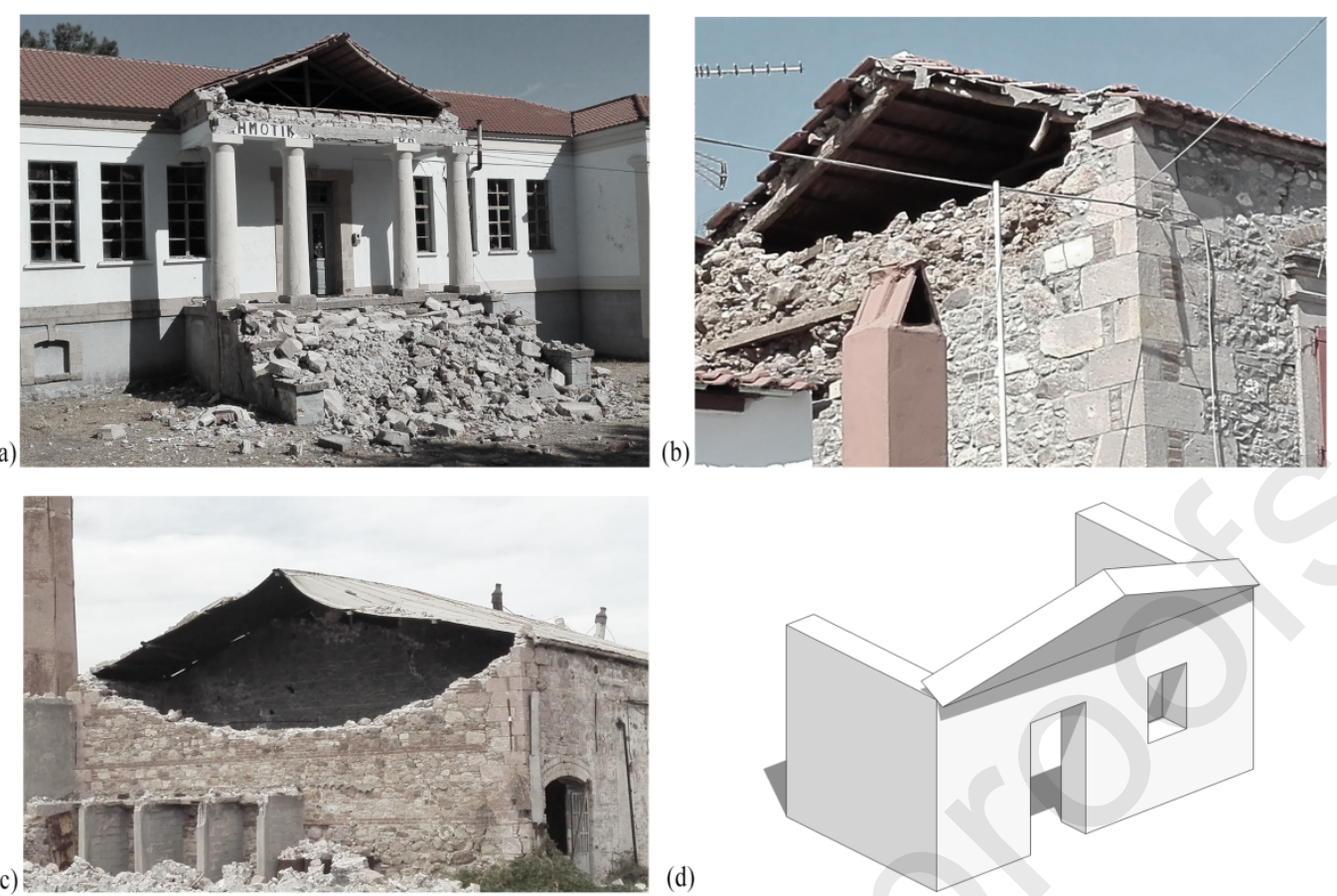

(d)

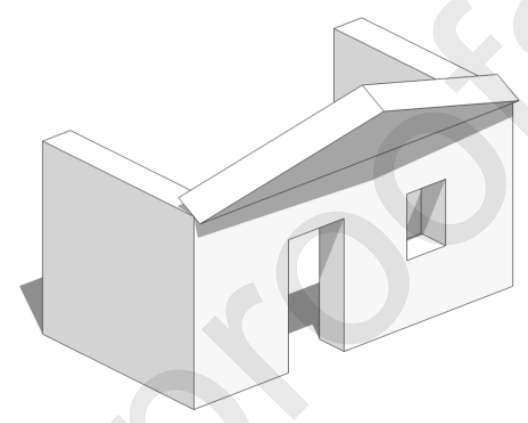

Figure 9. (a)-(c) Gable end wall overturning. Notice the presence of tie rods at the right corner of (c). Note that (a) is in the settlement of Vasiliko. (d) Schematic sketch of gable end wall overturning.

Another common local mechanism concerns the top part corners of buildings (Figure 10). This mechanism originates from the lack of a diaphragm; often in presence of adequate connections by the quoin-stones, preventing façade detachment and overturning [48,49]. As a result, a combination of IP rocking-sliding and OOP flexural failure occur, forming wedge type diagonal cracks. Furthermore, the vulnerability of this mechanism is increased by the presence of a thrusting roof, and neighboring openings or flues at the transversal walls. Finally, it should be noted that the occurrence of such mechanism reduces significantly the capacity of the connecting transversal façades, as they lose a vital transversal support.
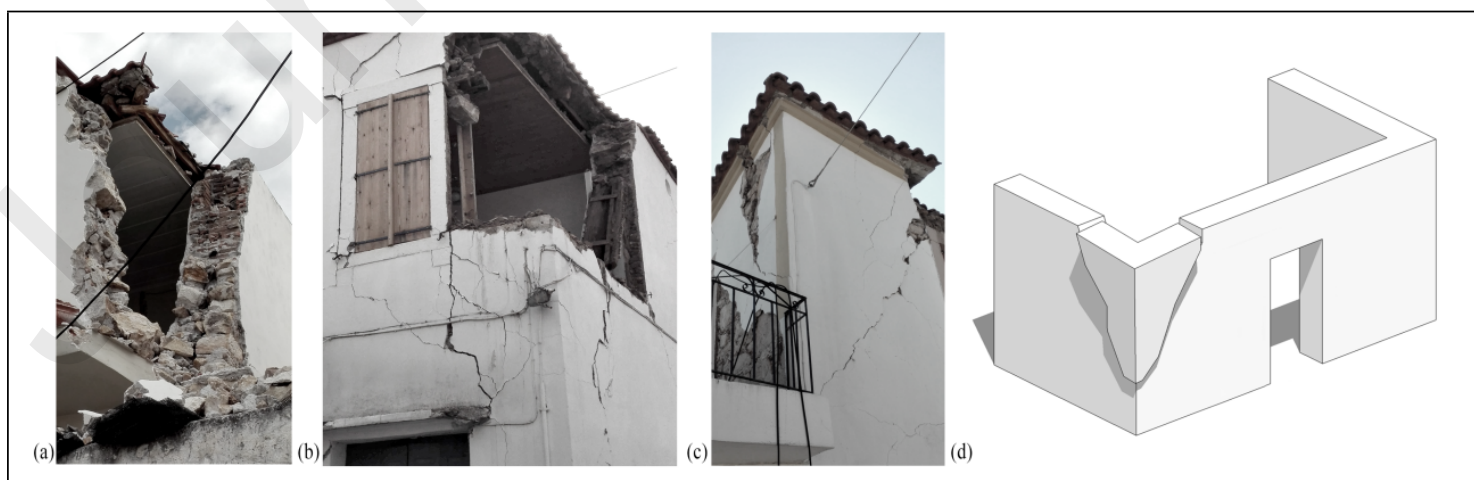

Figure 10. (a)-(c) Corner mechanisms. Note the presence of a flue in (a) with bricks in the stone masonry, and windows in (b). (d) Schematic sketch of corner mechanism.

Local failures were also observed in areas of fireplaces' flues (Figure 11). The usual configuration of embedding the fireplace's flue within masonry induces a local section 

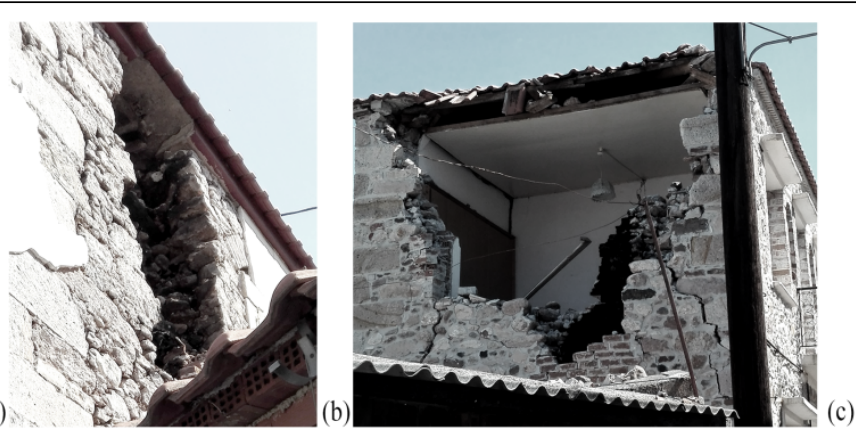

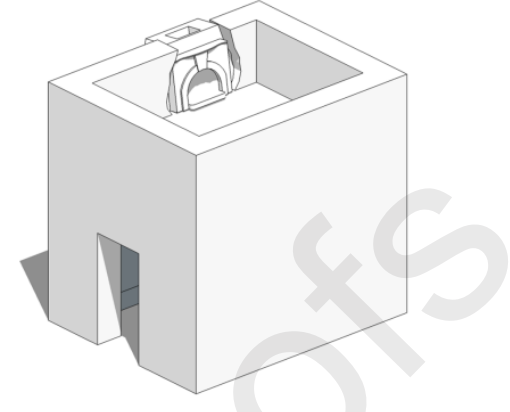

Figure 11. (a)-(b) Local failures in areas of wall-embedded fireplaces' flues and (c) corresponding schematic sketch.

284

\subsection{Out-of-plane Mechanisms}

In the absence of a "box like behavior" of structures, i.e. a global or integral behavior of the building induced by horizontal diaphragms that connect the structural in a unified response, the inertial forces of the walls perpendicular to the seismic action give rise to OOP bending. The capacity of masonry structures under such action is particularly low, and led to most collapses during the earthquake in Lesvos, alike similar events.

Long walls or walls with insufficient transversal support suffer vertical, one-way bending. In particular, the top part of the façades, usually inadequately connected with the roof, behaves as a cantilever about their base or the underneath floor level (rocking type of failure). Similarly, walls with adequately connected transversal walls experience two-way bending, characterized by larger capacity in comparison with the former. Figure 12 depicts typical OOP collapses. 


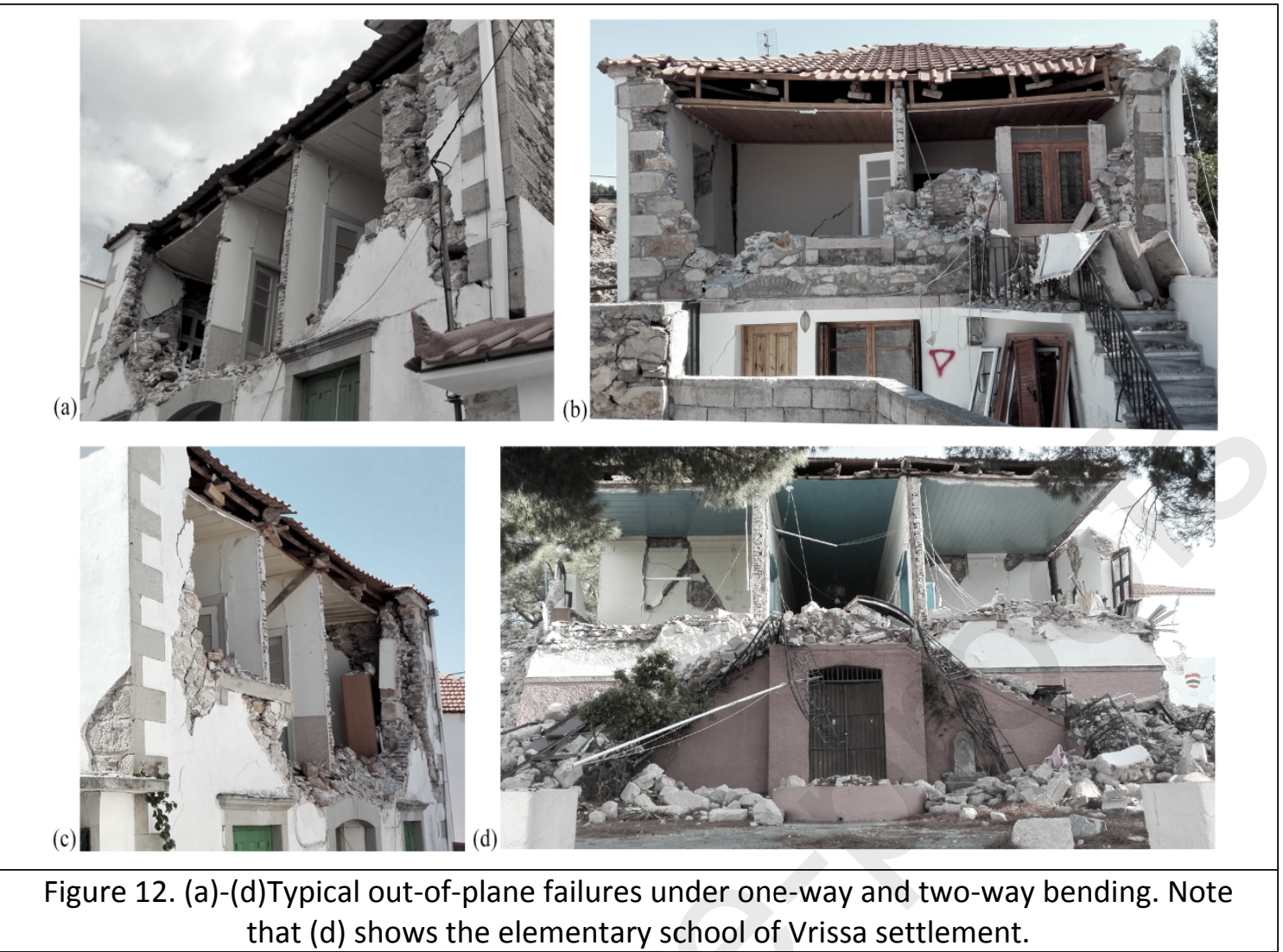

297 The typical plan layout of the constructions in the area contributed to the development of one-way OOP bending. Since the internal walls were not connected with the masonry walls, the resulting unconstrained length of the façades (around $10 \mathrm{~m}$ ) was too large. Several cases were observed in which one intermediate wall was shared between two structural units; yet one of them was just resting on the common wall, lacking connection. Such configuration usually appears when the two units were built at different periods, and the latter unit increased the internal space by utilizing the existing wall. The seismic vulnerability of such configuration is clear from a structural point of view, as the transversal façade of the latter unit lacks a lateral support (Figure 13). A traditional solution in such cases is the insertion of protruding (or "toothing") stones to ensure interlocking, although this was not observed in the field reconnaissance. 
(a)
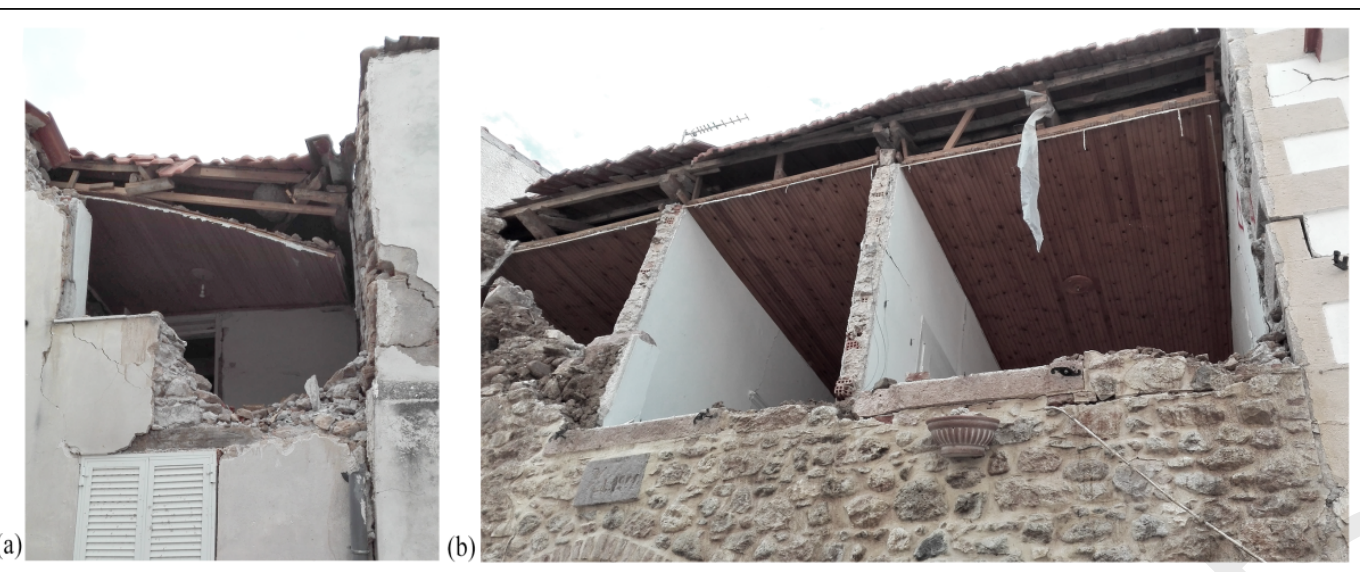

(1)
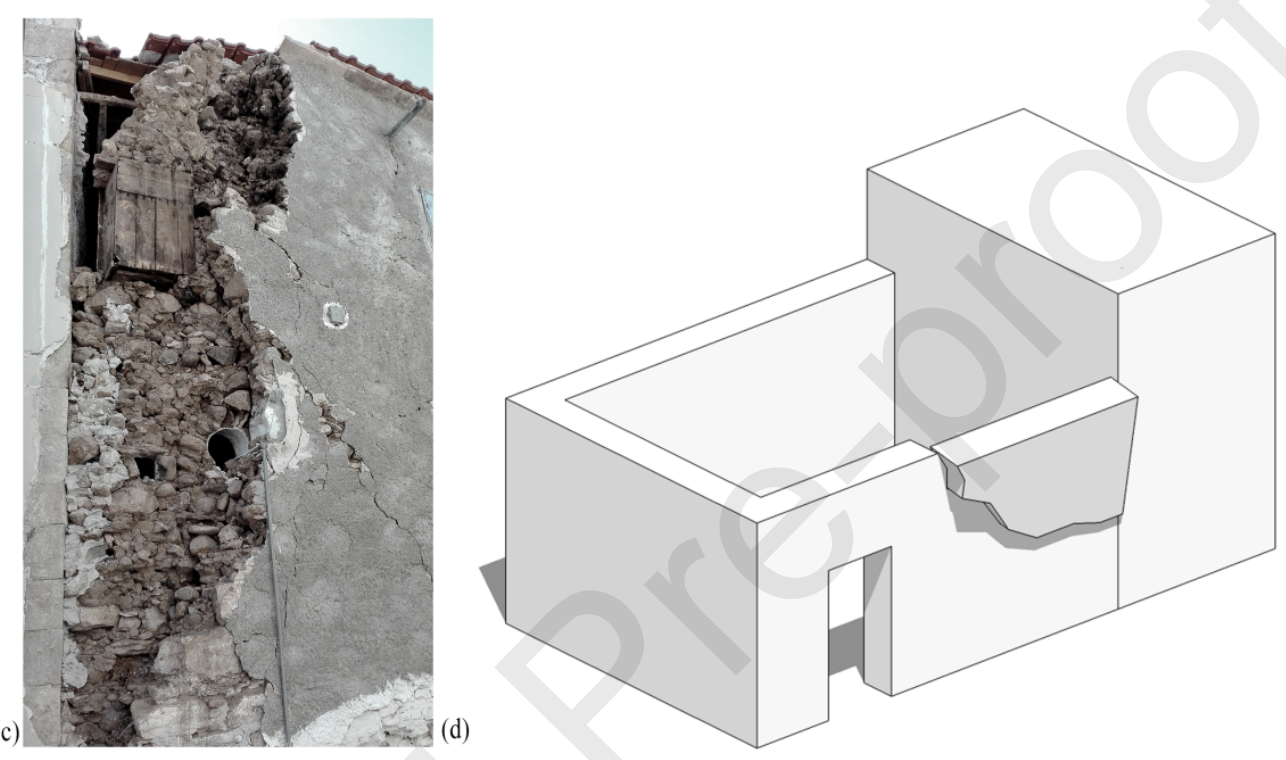

Figure 13. (a)-(c) Out-of-plane failures of façades with unconnected walls juxtaposed, with no interlocking, and (d) corresponding schematic sketch.

Furthermore, the presence of transversal walls is not a de facto guarantee of their effectiveness. An adequate connection capacity is required in order to distribute the inertia forces of the OOP façade to the in-plane walls, typically ensured by quoin-stones (Figure 5), timber-laces (Figure 6) or tie rods (Figure 9 (c)). The importance of the corner connections was appreciated by local masons, at it can be recognized by observing the existing construction details. However, in several buildings the quoins were not sufficient, especially when the second set of stones in a course was poorly constructed or missing, making a short connection. Moreover, the presence of openings at the proximity of the corners appeared to reduce the strength of the corner connections (Figure 14). In the same context of lateral support, the architectural feature of buildings' entrance with a recess door acted beneficially for the façades, introducing flanges (Figure 15). A representative example is shown in (Figure 15 (a)), where the transversal walls of the entrance recess suffered IP damage, indicating their role of supporting the main façade. Nevertheless, this attribute was only effective for the ground floor. 


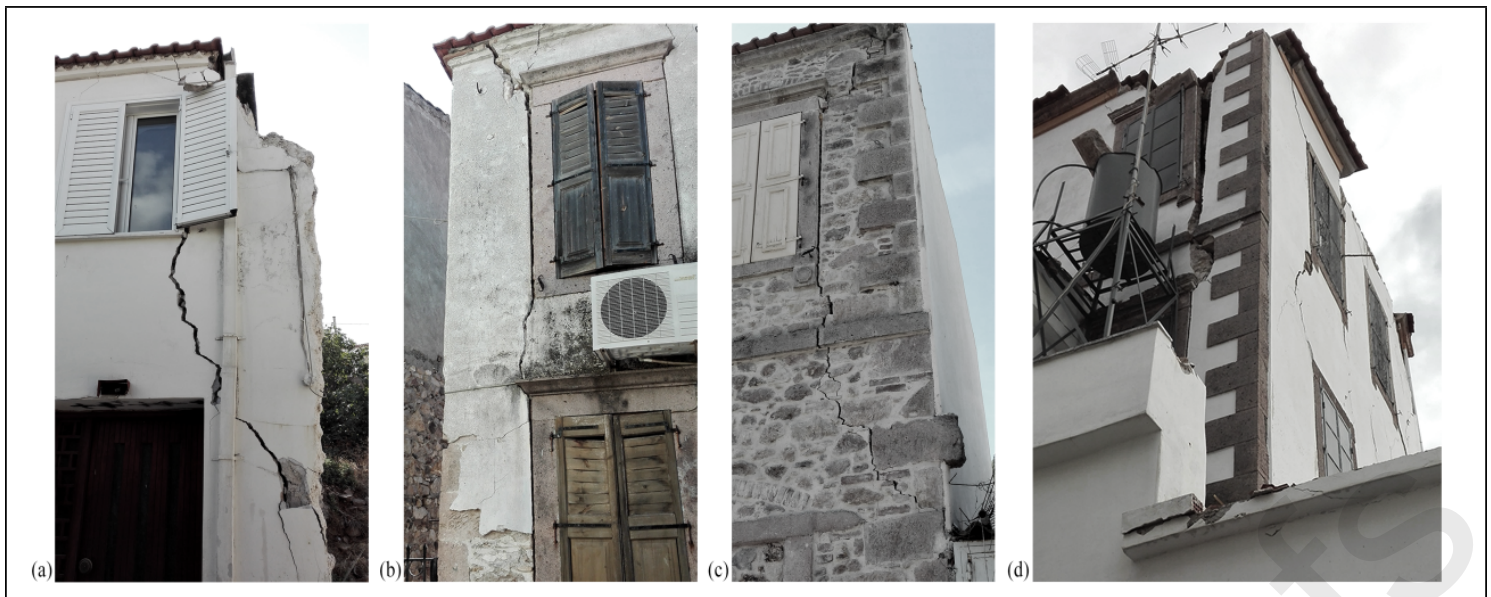

Figure 14. (a)-(d) Weak connection of transversal walls, due to the presence of openings at the corner proximity.

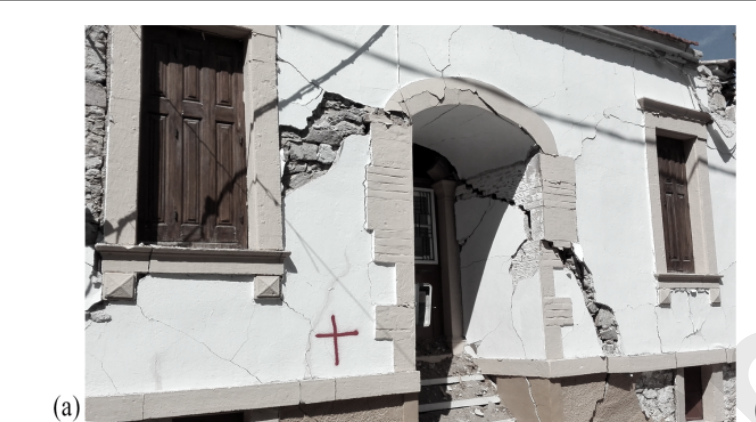

(b)

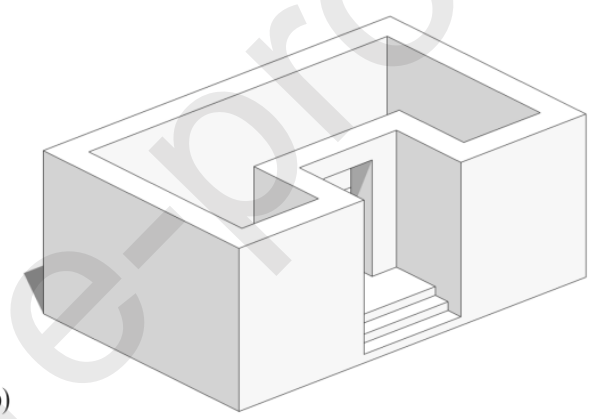

Figure 15. (a) Entrance recess provided transversal constrain to the façade, and (b) corresponding schematic sketch.

The vulnerability of the masonry walls is also governed by the slenderness, with more damage for walls with higher interstory height. Due to the acceleration amplification across the height and the lower overburden weight, many OOP collapses of top parts of slender walls were observed (Figure 12). A representative example of the aforementioned characteristics can be recognized in slender downhill side façades (Figure 16).

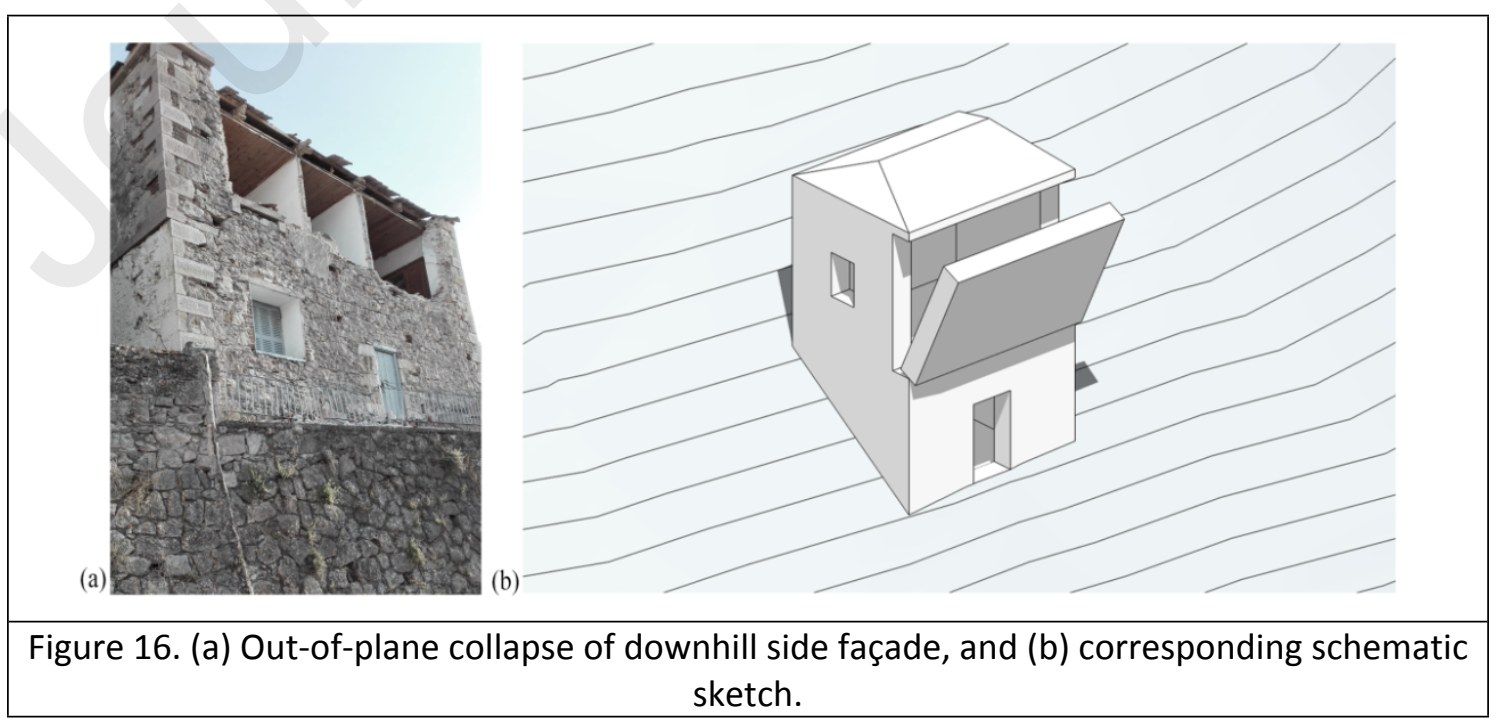


It is well known that horizontal elements can contribute to prevent OOP failures by constraining the façade; yet insufficient connections with the masonry walls were observed for these elements. With the exception of the cases with timber laces, the timber roofs and floors were simply resting on the masonry walls, thus possessing only limited frictional horizontal capacity, which was inadequate to cope with OOP inertia forces. Moreover, the floors were spanning only in one (main) direction, supported by two parallel walls. Therefore, transversal walls were not connected by the horizontal systems, a necessary condition for diaphragmatic action. A few cases of localized damage due to thrust action of the roof were observed (Figure 17). It should be noted that timber sill plates were employed at the end of the timber beams, in order to distribute smoothly the gravity forces, thus avoiding local wall failures (Figure 12 (a)-(c)).

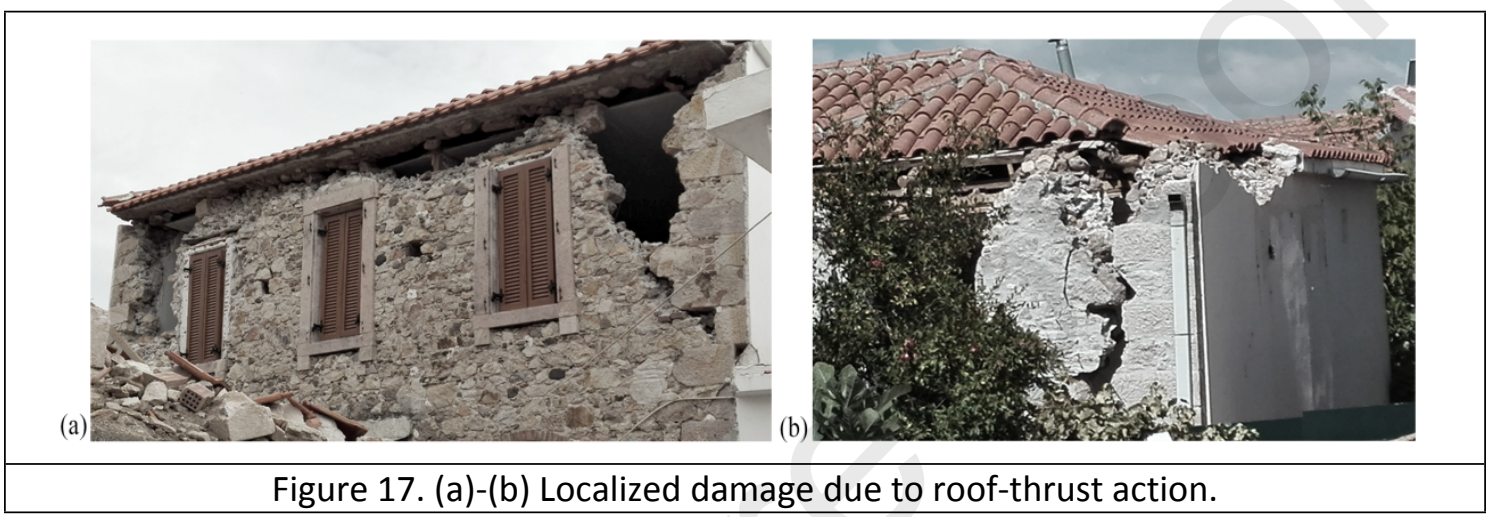

Plan irregularities led also to OOP mechanisms. Figure 18 (a) shows a protrusion of a building that concentrated severe damage due to torsional phenomena taking place. Figure 18 (b)-(c) displays a case of complete collapse of the first floor. By looking to its condition before the seismic event, it appears that the owners demolished the corner of the building at the first floor in order to create a balcony. This eliminated any connection of the transversal walls and introduced a plan irregularity, certainly contributing to collapse.

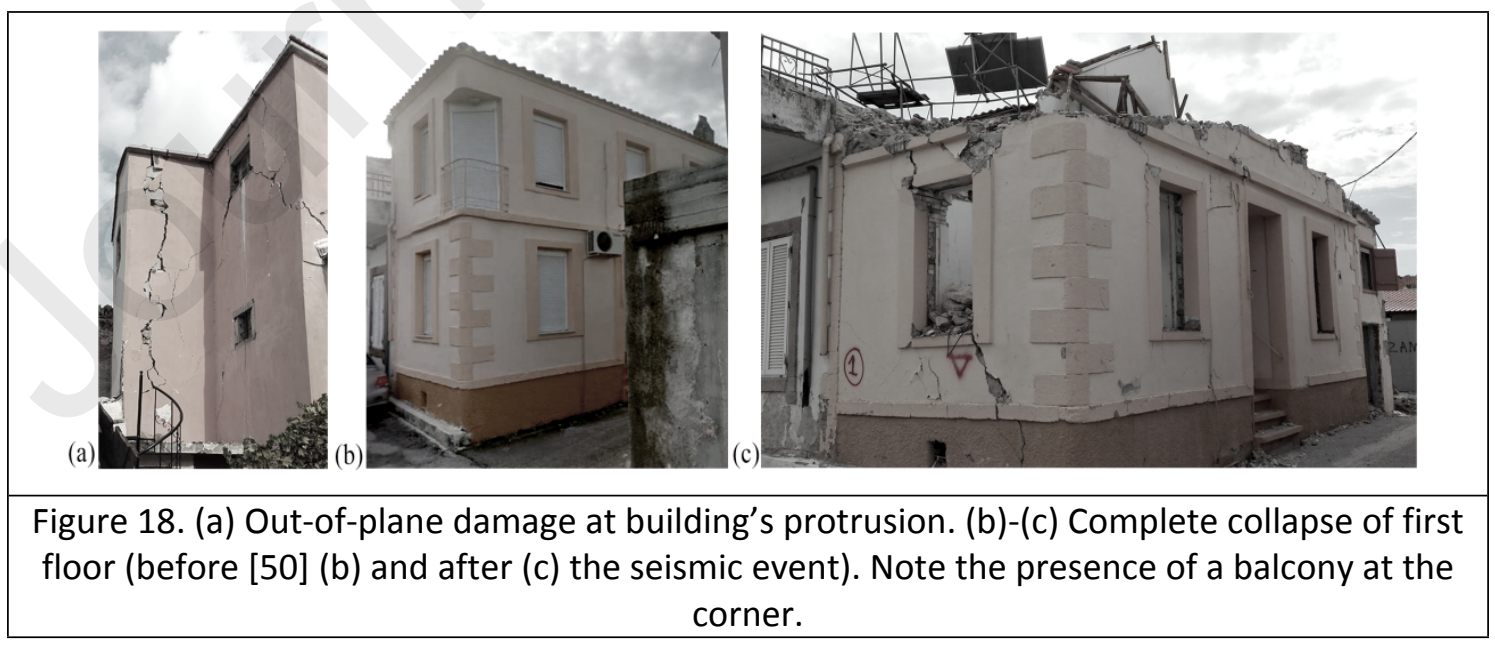

\subsection{In-plane Mechanisms}

349 The IP response of masonry structures is in general preferred, as it utilizes the largest capacity of the walls, dissipates significant energy and provides less brittle collapses. In fact, 
351 in such cases damage tends to be prevented, unless the in-plane area of masonry walls is too low or the openings are badly positioned. The mobilization of IP behavior requires the prevention of local and OOP mechanisms, usually with the help of a diaphragm or densely spaced transversal walls. During the field reconnaissance, typical IP damage patterns were observed and are described here.

In most buildings where the plan and elevation regularity is respected, damage is distributed in the so-called masonry members, i.e. the piers and spandrels. On the other hand, buildings with irregular configuration exhibit damage concentration at the weakest areas (Figure 19).

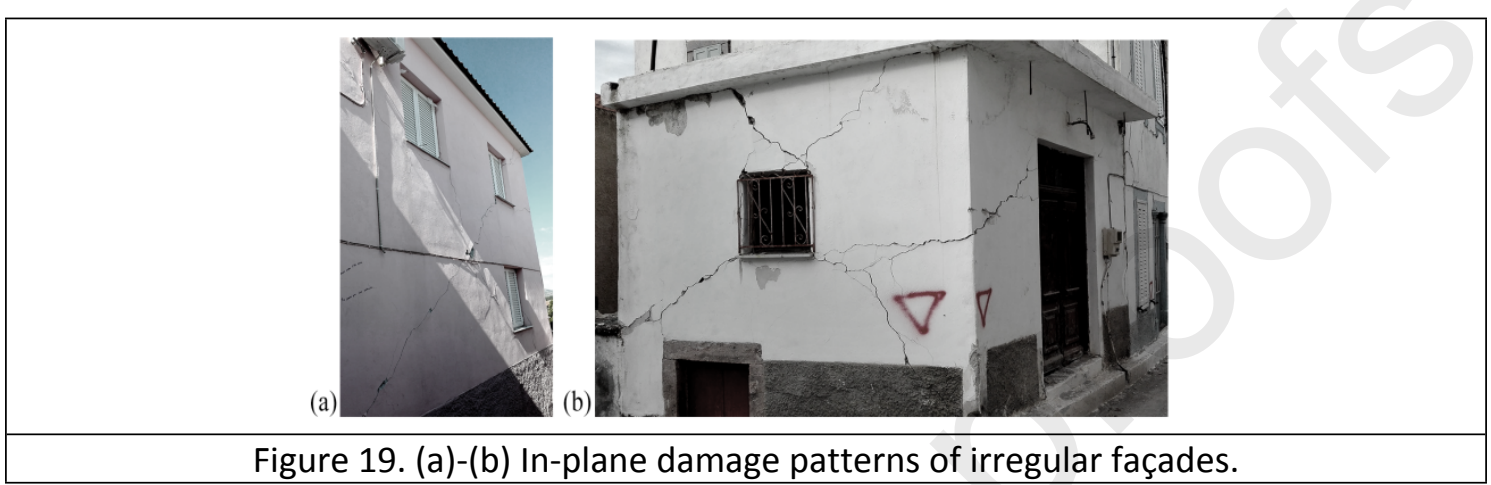

Shear damage, usually exhibited by squat walls, appears mostly as diagonal tension with joint sliding in case of good quality masonry. The diagonal tensile mechanism occurs when the principal tensile stress at the center of the member reach its tensile capacity. This mode is characterized by larger brittleness, while it develops as a pair of diagonal $X$ cracks over the member, in the case of rubble masonry with almost straight cracks. The joint sliding mechanism takes place when the frictional capacity of the member is exceeded. This mode shows a ductile behavior, and appears either as a pair of $X$ stepwise cracks or as horizontal crack over the member (the latter more uncommon). Flexural damage affects mainly slender members. It appears at the member's end sections (e.g. top or bottom for piers) either as tensile cracks or as toe-crushing. This damage mode exhibits large displacement capacity, until toe crushing occurs. Finally, any combination of the aforementioned modes is commonly observed, especially after cyclic loading reversals. Figure 20 illustrates representative cases of the aforementioned IP damage patterns. 


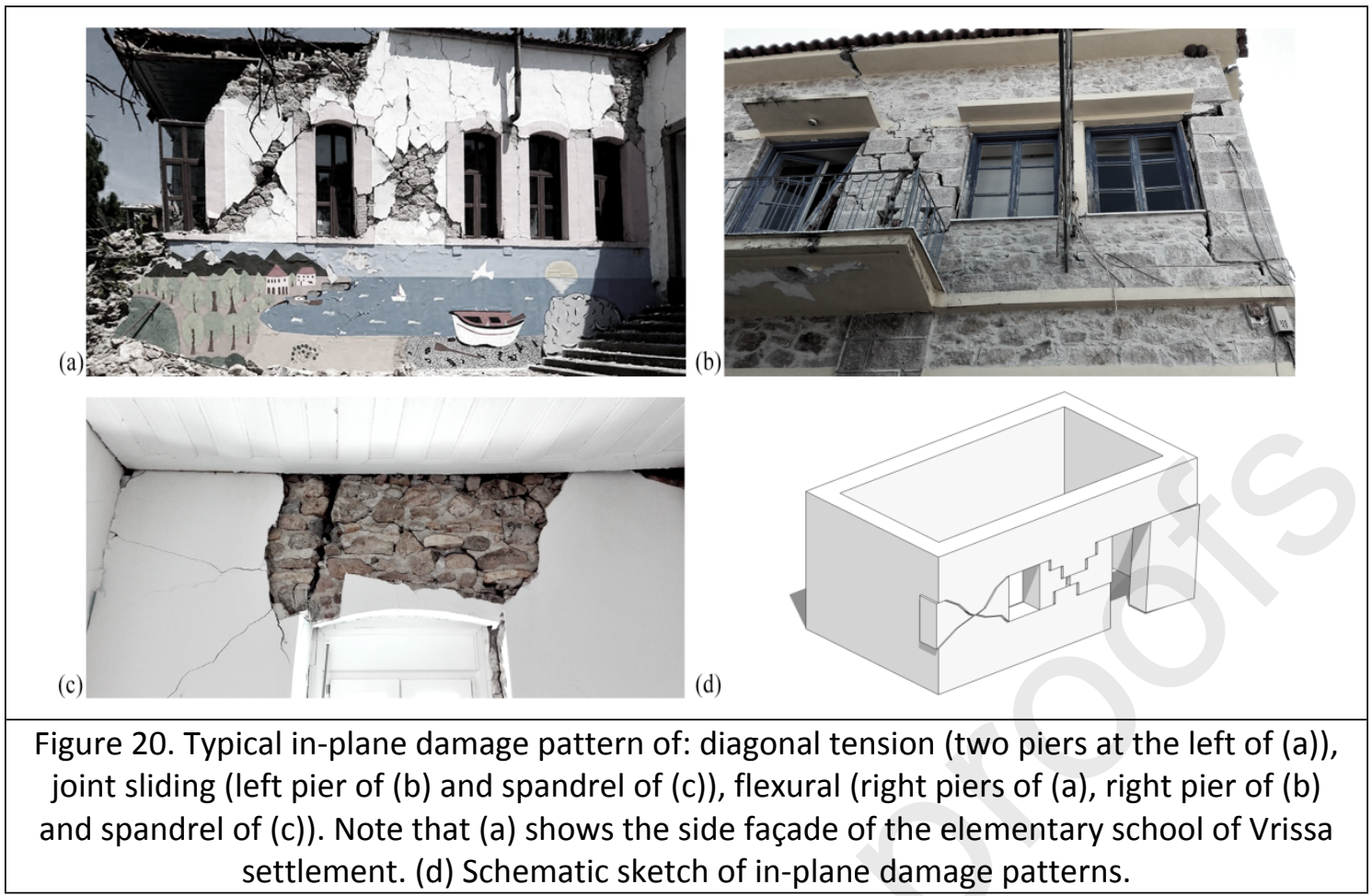

As expected, URM structures that experienced IP damage were mostly cases with a Reinforced Concrete (RC) slab (Figure 19 (a)-(b), Figure 20 (b), Figure 21). By its inherent stiffness, the slab acts as a diaphragm and thus prevents OOP mechanisms. Nevertheless, it should not be disregarded that RC slabs possess significant weight and therefore increases also, moderately, the seismic demand (in masonry buildings most of the weight remains in the walls). Figure 21 illustrates a building with particularly large mass due to the RC slabs that even extend to balconies, with severe IP damage in the ground floor.

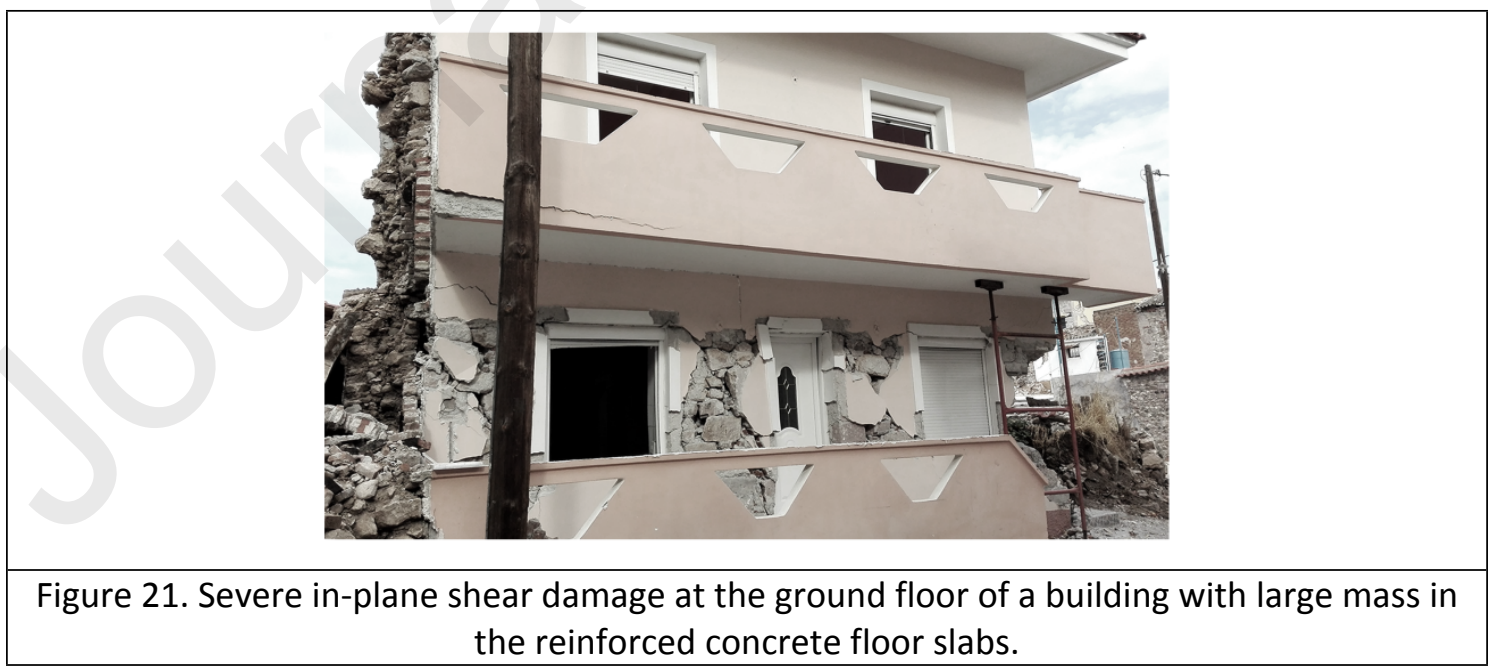

\subsection{Combined In-plane and Out-of-plane Mechanisms}

Except the distinct occurrence of IP or OOP damage mechanisms, three combined IP and OOP mechanisms were observed and recorded during the field reconnaissance. It is of interest to note that combined mechanisms are poorly studied in literature, especially in terms of available methodologies for assessment and design. 
(a)

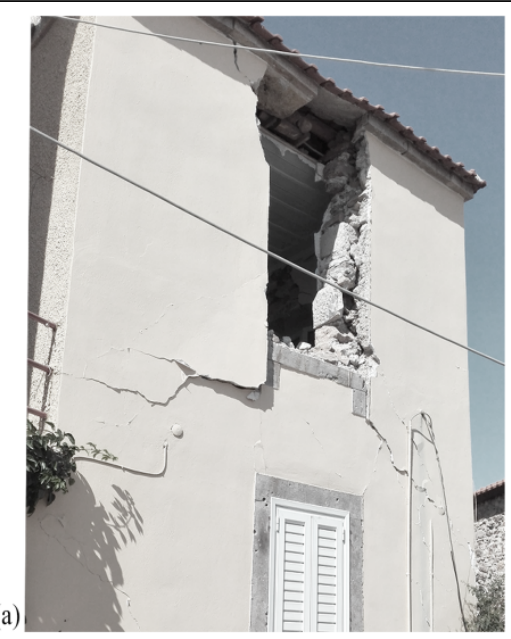

(b)
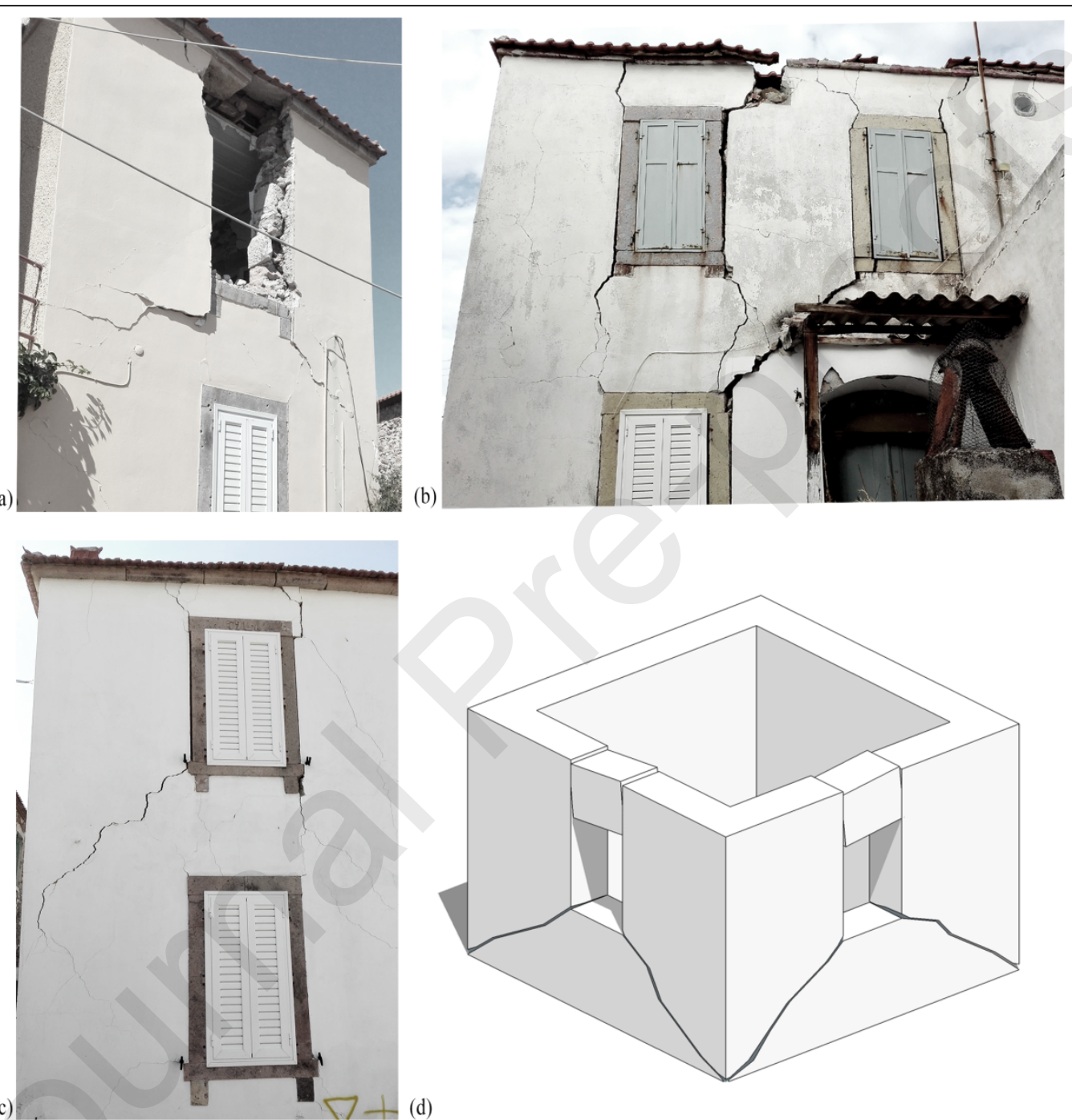

Figure 22. (a)-(c) In-plane and out-of-plane interaction mechanism, and (d) corresponding schematic sketch.

The most frequent combined mechanism was the interaction, leading to both: 1) vertical cracks at the end sections of the spandrels that derive from the IP flexure of the spandrel and the OOP response of the façade; 2 ) diagonal cracks at the lower corners of the openings propagating towards the corners of the structure, that arise by the IP shear damage and the OOP behavior of the façade (Figure 22). An additional characteristic of this mechanism is that in most cases it appears mirrored in the transversal façades. The corner mechanism, mentioned in Section 3.1, is a local manifestation of this mechanism.

Observed only in a few cases, another identified combined mechanism was the wedge biaxial failure. This appears as a second order mechanism of the previous combined, when the top part of the construction is restrained. Under this condition, a wedge (usually the corner of the building) is highly stressed by the biaxial actions up to its capacity, resulting in a bursting collapse (Figure 23). In case of corners, the failure surface forms a rhombus that expands over the two transversal walls. In addition, this mechanism was also observed at the recess corner of a plan-irregular structure, where high biaxial stresses concentrated 
401

402

403

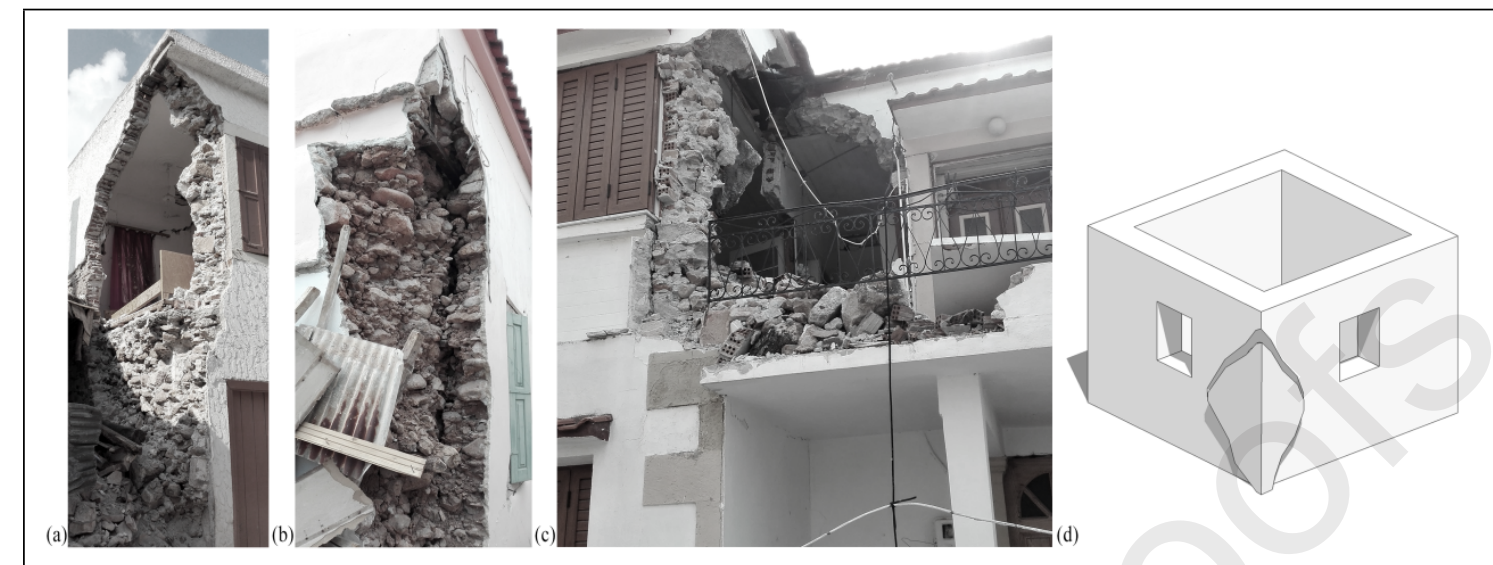

Figure 23. (a)-(c) In-plane and out-of-plane biaxial wedge mechanism, and (d) corresponding

(Figure 23 (c)). It may be worth mentioning that cut corners, a commonly observed functional detail for street widening (e.g. see the bottom part of the corner at Figure 5 (a)), significantly reduce the capacity of this mechanism.

$$
\text { schematic sketch. }
$$

405 Another combined mechanism observed was the OOP collapse of a previously IP damaged 406 wall. This mechanism refers to the strength degradation induced by IP damage to a portion 407 of the masonry wall, which may then be isolated and overturned by OOP actions (Figure 24). 408 The reverse situation was not observed in the field reconnaissance, but it should not be 409 excluded. 
(a)
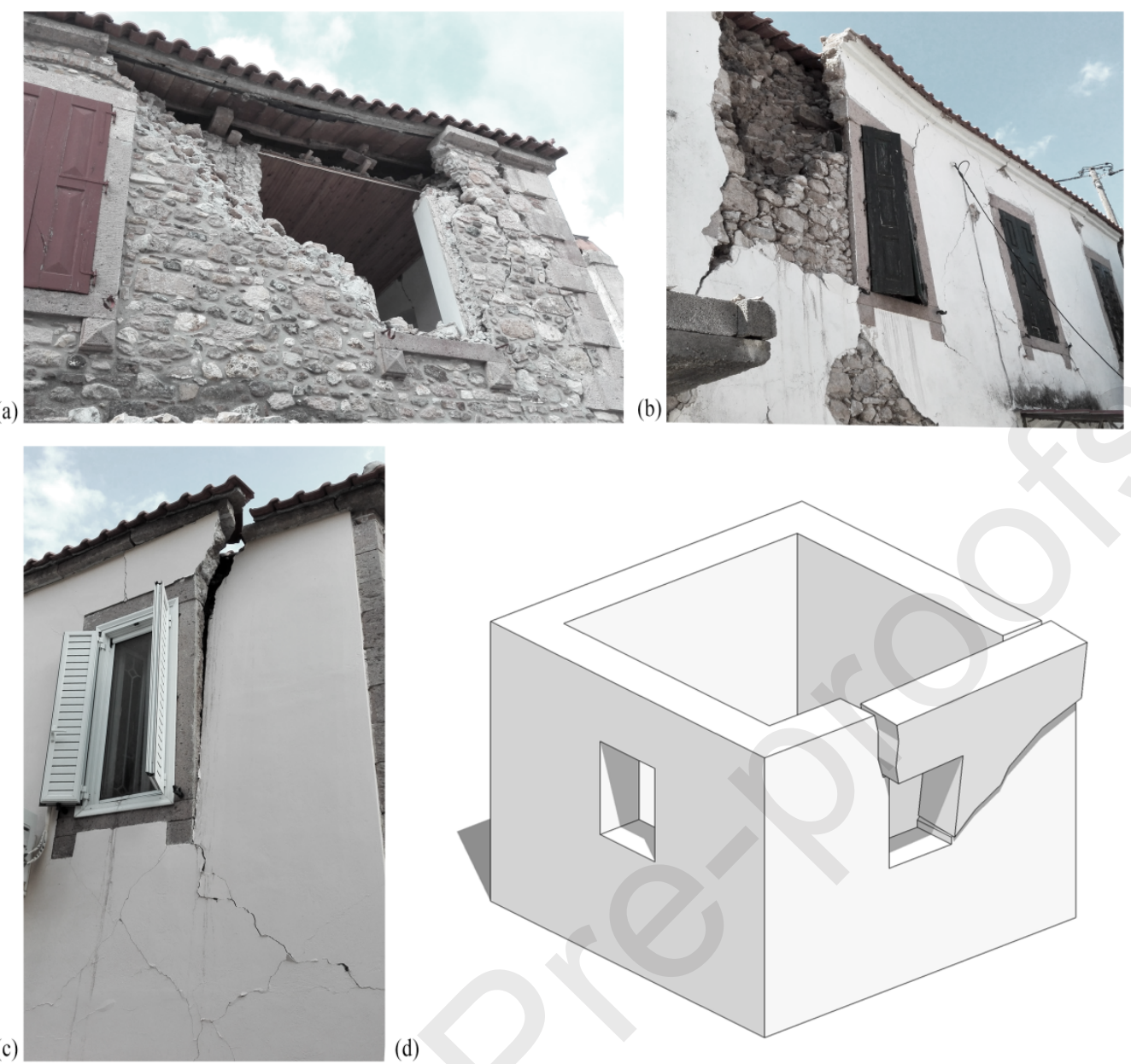

(d)

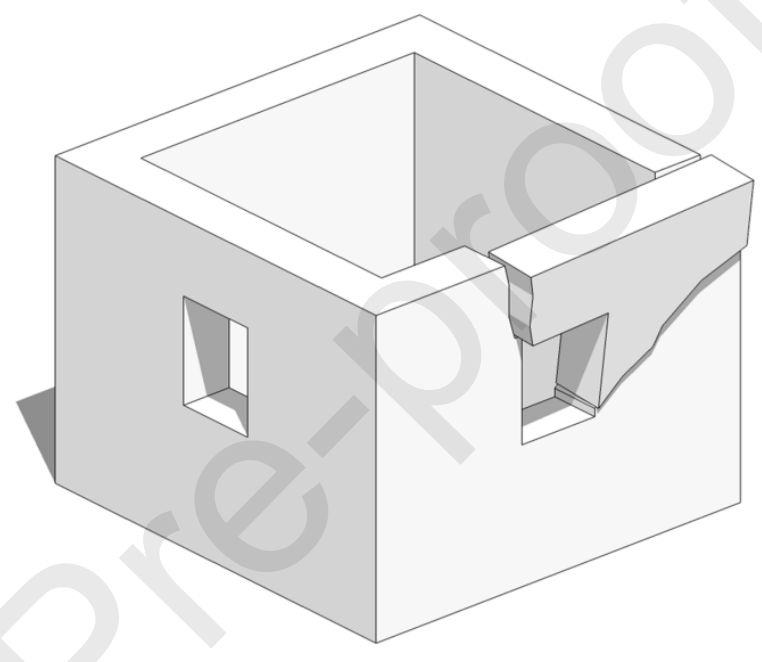

Figure 24. (a)-(c) Out-of-plane collapse of in-plane damaged members, and (d) corresponding schematic sketch.

\subsection{Non-structural Components}

Damage or failure of non-structural components is often associated to significant economic losses, loss of functionality and potential threats to life safety [51]. Therefore, the damage induced to non-structural components was recorded and is presented herein.

Similarly with previous earthquake reconnaissance, collapses were observed in retaining and veneer walls (Figure 25 (a)), pillars (Figure 25 (b)), chimney tops (Figure 25 (c)), roof tiles (Figure 25 (d)) and infilled window openings. Yet the most crucial and widespread of nonstructural failures appeared to be the monolithic stones used for posts and lintels of the openings (Figure 25 (e), (f)). As discussed in Section 2.2.1, this local architectural feature of the settlement did not possess any connection or interlocking with the rest of masonry and thus detached easily. More importantly, collapse could undoubtedly lead to fatalities, as massive stones collapsed at the entrance of the buildings and in the streets during the seismic event. 


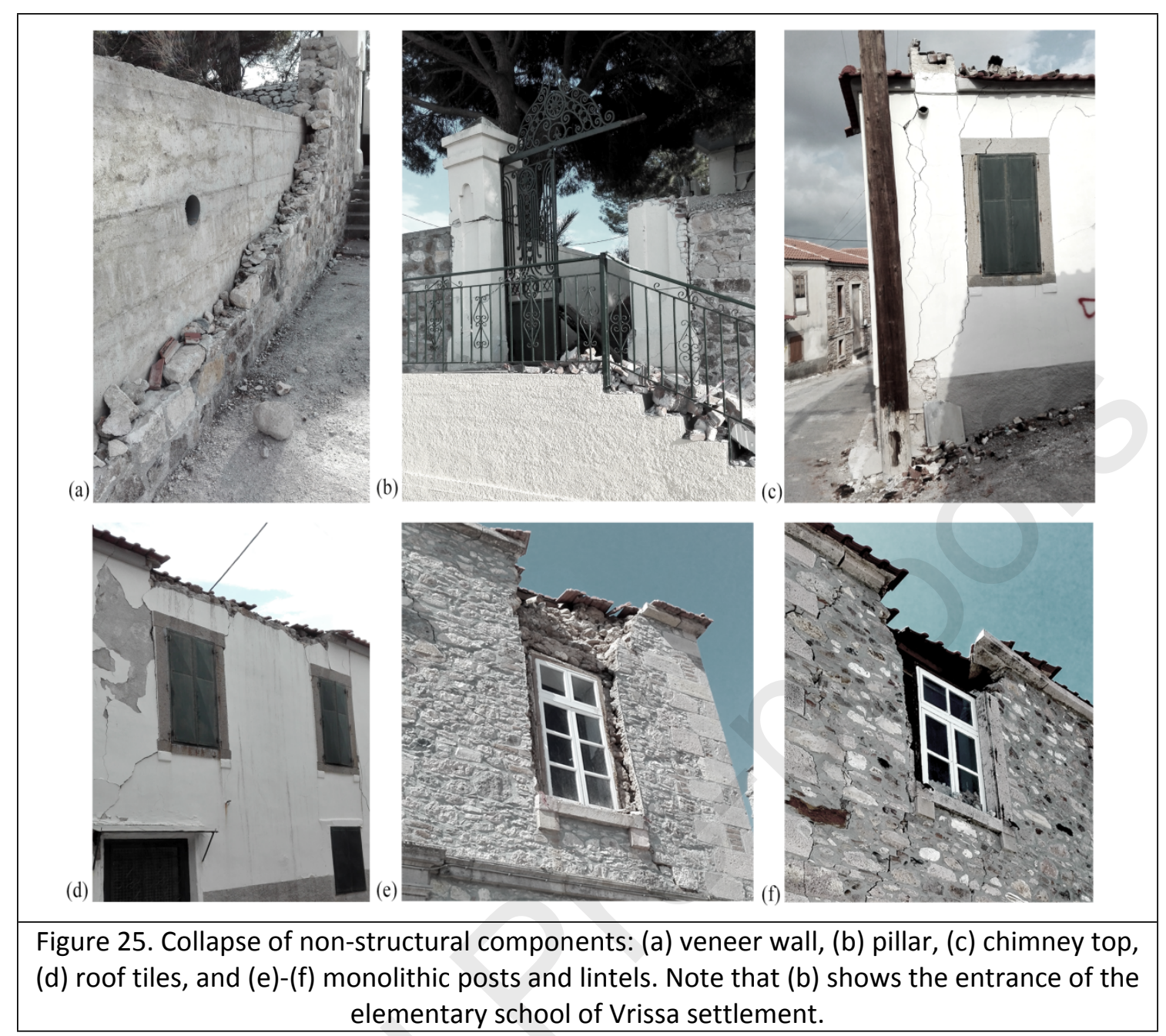

\section{Interventions}

It is usual that old structures undergo some kind of intervention during their lifetime. Such actions may alter, or fail to alter, the seismic response of the structure. The existing knowledge of the effect that interventions have on masonry structures is generally limited; especially when referring to real applications, where the controlled conditions and assumptions of the laboratory testing do not necessarily apply. This stresses the need to assess the effectiveness (or vulnerability) of interventions by studying their performance in actual seismic events.

A remarkable example of the lessons learnt after seismic events is Italy. Destructive earthquakes that hit Italy in the 1970's and 1980's led to the adoption of strengthening measures in the national codes as well as actual applications to reduce the seismic vulnerability of masonry structures. However, the effectiveness and compatibility of many of the adopted techniques was questioned deeply after the seismic events that followed in the next decades, as their performance was tested [16,19,25,52-54]. Thus, the national codes were changed, limiting and even banning some of the techniques adopted in the past. Nevertheless, studies of more recent seismic events highlighted that strengthened structures according to the past seismic codes performed better than non-strengthened structures, which is in disagreement with the previous outcomes [21,37]. 
Two aspects become clear from the past observations: 1) documenting the performance of previous interventions after a seismic event can highlight their benefits and reveal their shortcomings; and 2) the choice and application of intervention measurements for masonry structures is a nontrivial task in engineering that should be carried out with caution. In fact, as [16] stated, "there are not bad techniques but only inappropriate and poor applications due to lack of knowledge and of skillness [sic]". Nevertheless, well-considered and wellapplied interventions have persistently shown an enhancement in the seismic performance, being encouraging and promising for future developments [21,27,37,55].

Keeping in mind the above, the following paragraphs attempt to shed light in the performance of observed interventions, while drawing meaningful conclusions. A basic distinction is pursued, based on the scope of the interventions: a) those that aim to restore, strengthen or upgrade the structural unit; and b) those that aim to change or redefine the use of the structural unit, causing structural alterations.

\subsection{Performance of Strengthening Techniques}

Firstly, interventions that have the explicit intention of improving the structural behavior are studied. Three categories of interventions are considered according to the purpose:

1. To ensure the integrity and solidity of the masonry assemblage

2. To ensure the connections of structural elements

3. To increase the capacity or stiffness of structural elements

This categorization may be understood also as a strengthening hierarchy (or prioritization). In principle, the integrity of masonry comes before adequate connections of structural elements, which in turn come before enhancing capacity of structural elements for better seismic performance. In other words, interventions that increase the capacity of structural elements would be less relevant, if the different elements are not adequately connected; while, the assurance of structural connections would not be fruitful, if the masonry disintegrates. This framework can assist in interpreting the observed performance of previous interventions.

Several cases were identified in which a RC beam was introduced at the top of masonry walls (Figure 26 (a), (b)). This strengthening technique falls in the second category and could be beneficial, as it connects and ties the transversal walls (and may add overburden weight), thus reducing the OOP vulnerability of the façades. Nevertheless, local or even global collapses were observed in such cases, with the masonry walls disintegrating ("zero" mechanism). Given the extremely poor quality of masonry, the integrity of the underlying walls was not ensured in order for the enhanced connections to be beneficial. In addition, one could argue about the damage introduced by adding the beam or the subsequent incompatibility of deformation, and about an increase in the demand of the poor masonry walls, due to the added mass of the RC elements, or the destabilizing OOP moments that arise by an eccentric interaction at imposed deformations (p-delta effects) [56].

A similar response was seen in cases that a RC slab had substituted the roofing system (Figure 26 (c)). The addition of a rigid diaphragm was not able to improve the seismic 
response of the underlying poor masonry. Had the masonry's integrity been ensured, the diaphragm could be beneficial.

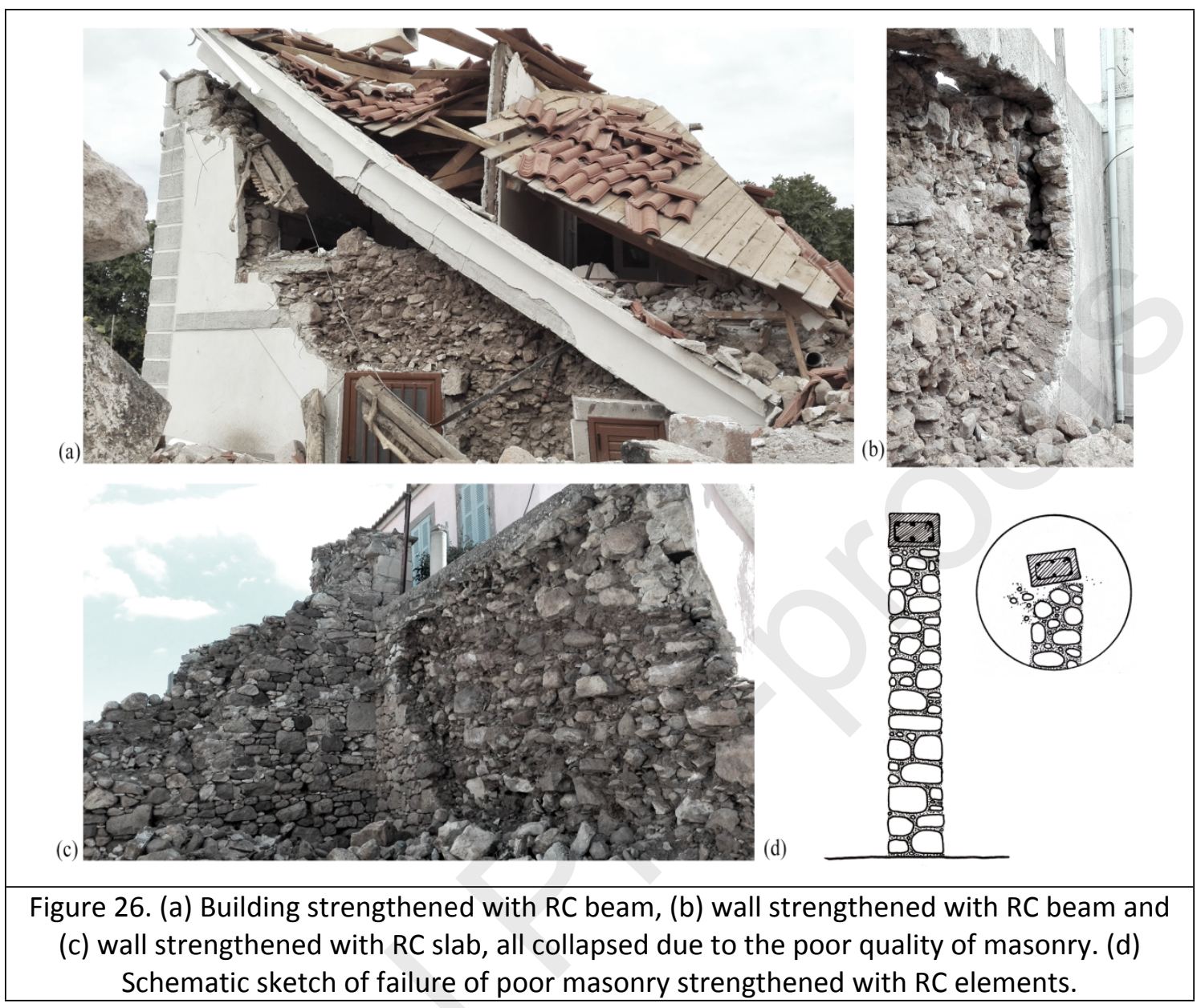

Finally, a few cases of RC jacketing were observed. This strengthening technique falls in the third category, as it intends to increase the capacity and stiffness of the masonry walls, both for IP and OOP actions. However, as the application was once more over a poor masonry substrate, failure and collapse were found (Figure 27). At this point it is interesting to note that if a proper detailing is performed, with applications on both sides of the walls and welldesigned anchors, RC jacketing could act beneficially also for the integrity of the masonry, i.e. the first category. Nevertheless, very deficient applications of this strengthening technique were found (Figure 27 (c)), as application was only on the internal surface and using sparse anchors. The images illustrate clearly that it was masonry that failed rather than the reinforcement, corroborating the need of prioritization of strengthening interventions. 


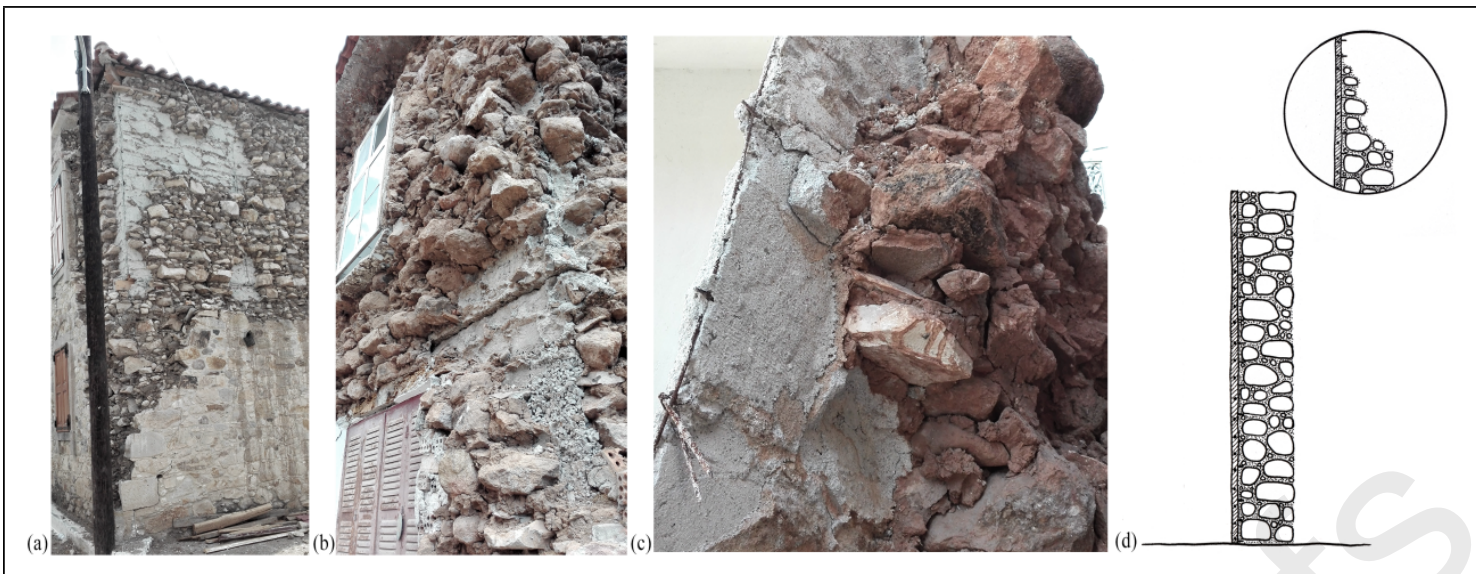

Figure 27. (a)-(b) Buildings strengthened with RC jacketing, which failed due to the poor quality of masonry. (c) Detail of a collapsed masonry portion strengthened with RC jacketing. (d) Schematic sketch of failure of poor masonry strengthened with RC jacketing on one side.

\subsection{Additions and Alterations}

Some interventions are not intended to ensure or improve the structural behavior, but are only realized for functional purposes. A common misunderstanding seems to be present in such cases: since these interventions do not alter significantly the structural system, an engineering assessment of the structural unit is not necessary. As a result, some alterations are badly conceived and might end up being determinant for the structural unit's performance. Several didactic cases were observed during the field survey.

A frequent intervention is the substitution of the timber floors with RC slabs, basically arising by the easily availability of the material, cost and modern needs of the flooring system. In order to avoid drastic measures over the existing masonry, some engineers resort to the solution of adding an internal RC frame separate from the existing structure. The new internal RC structural system is designed independently of the external existing masonry, and no connection is enforced. Some cases of this configuration were inspected, among which one appeared to be catastrophic (Figure 28). Being disconnected, the two structural systems were characterized by distinct dynamic properties. During the seismic event this resulted in different displacement demands and at the same time out-of-phase responses, causing pounding phenomena. The stiff and heavy RC caisson collided with the masonry walls, inducing severe damage instead of providing strengthening to the existing structure. In fact, the failure mechanism of the masonry structure observed highlights the behavior, as the collapsed façade failed under OOP actions exactly at the height of the slab, while the two transversal walls suffered IP damage that initiated at the aforementioned height and propagated diagonally, ignoring the openings' layout. 
(a)
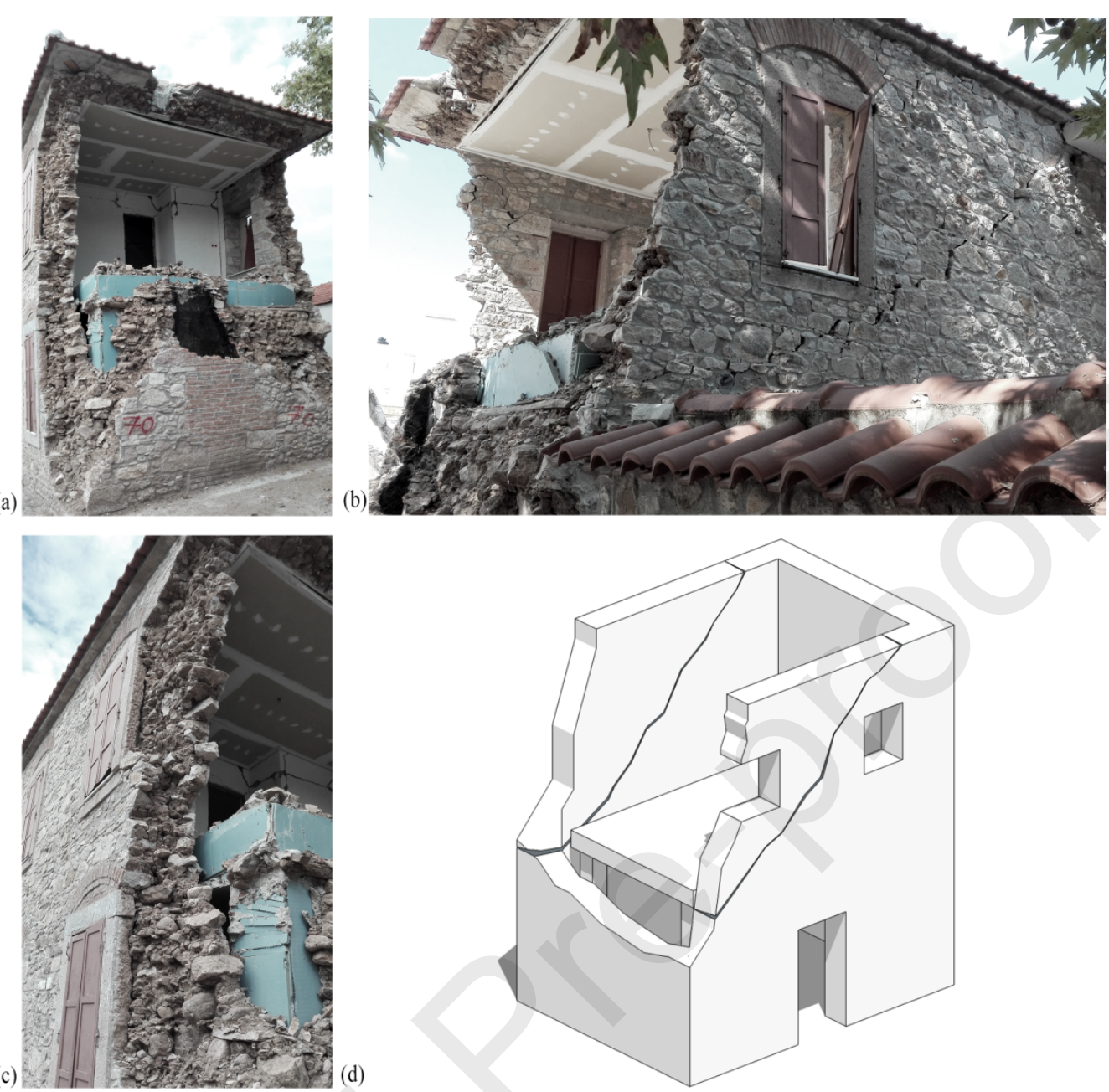

Figure 28. Pounding of external masonry and internal RC frame with slab: (a) general view of out-of-plane collapsed façade, (b) side view showing the diagonal crack, (c) closer look at the internal RC system, and (d) schematic sketch of the configuration. Note that the light-blue color is thermal insulation that covers the RC elements.

A similar intervention scheme inspected included RC columns and beams, the latter resting on the peripheral masonry façades. In this case, a proper connection among the new RC beams and the masonry walls was not ensured, resulting into two main damage patterns: 1 ) in cases of poor quality of masonry, the concentrated loads caused local disintegration of masonry (Figure 29 (a)); 2) pounding between masonry and the concrete beams caused damage to the façades (Figure 29 (b), (c)). 


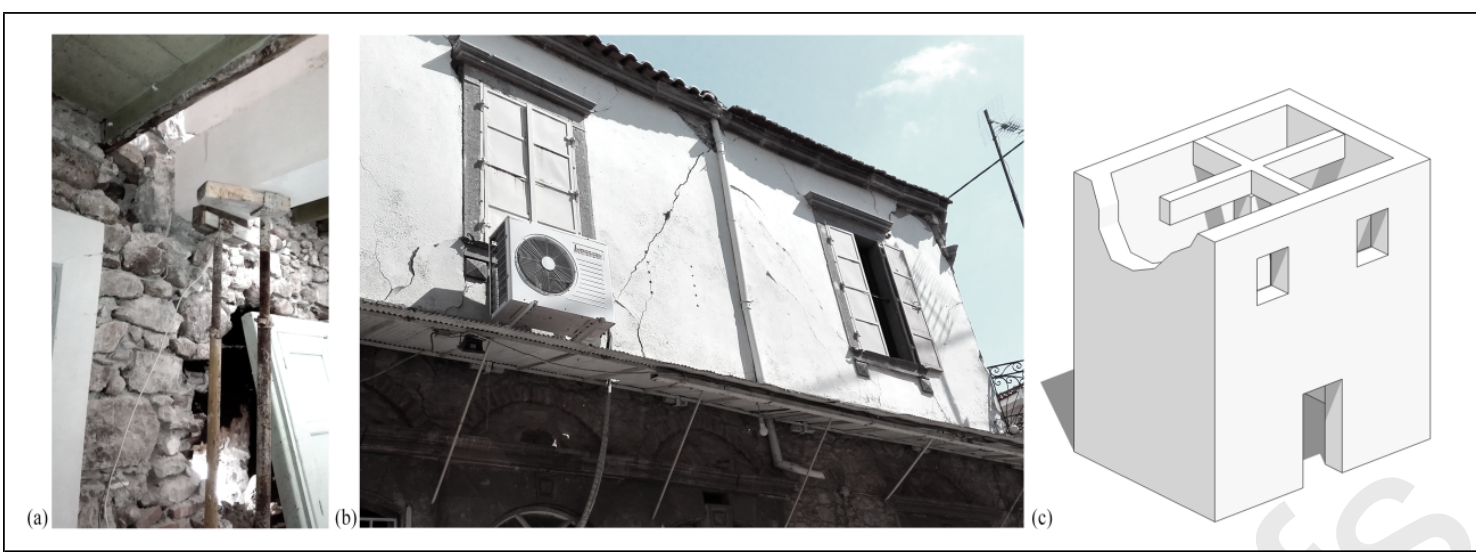

Figure 29. (a) Local damage caused by RC beam resting on poor masonry. (b) Pounding between internal RC frame and external masonry, and (c) corresponding schematic sketch. Notice the diagonal cracks starting from the top of the drainpipe.

Interventions that induce irregularities might end up being also decisive for the global structural integrity. The building shown in Figure 18 (b)-(c) and described in Section 3.2, is a representative case of this category of interventions with a disastrous outcome.

Finally, small additions are also a common intervention practice to increase the housing space. Additions across the height (in elevation) were observed in some cases to suffer detachment and potential overturning (Figure 30 (a)). Additions by side (in plan) often acted beneficially as a buttressing element, constraining the OOP failure. Nevertheless, pounding between the old masonry and the side addition was also identified (Figure 30 (b), (c)).
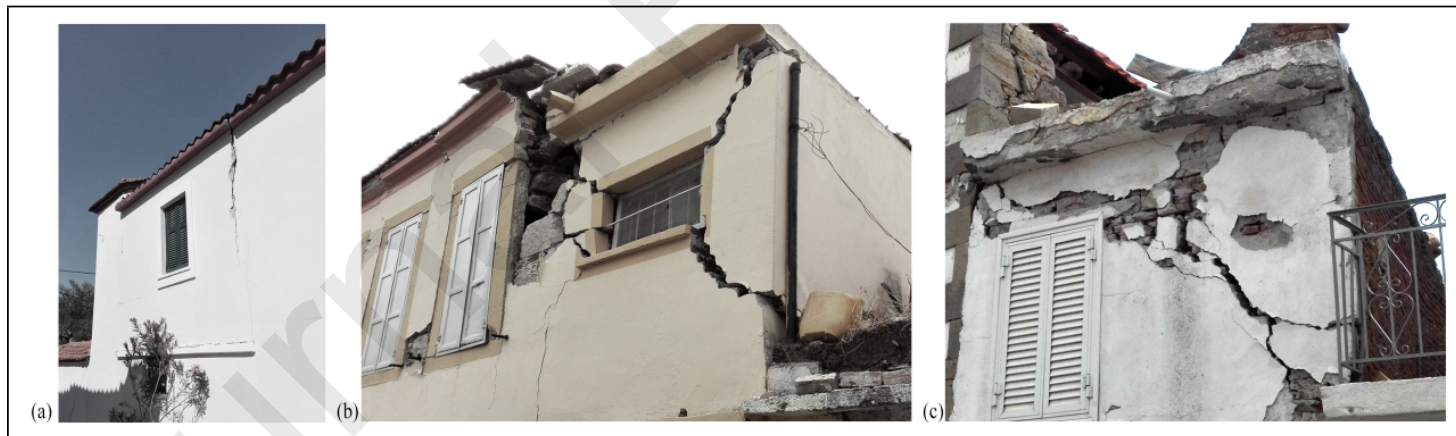

Figure 30. (a) Detachment of addition across the height. (b)-(c) Pounding of additions by side.

\section{Summary and Conclusions}

The 2017 Lesvos earthquake induced severe damage to old URM structures at the southwestern part of the island, and especially in the traditional settlement of Vrissa. Following previous research that pointed out significant damage in those structures, this paper discusses the factors that played a role to their performance. To this end, a field reconnaissance has been conducted in order to record damage and failure patterns, and in turn draw meaningful conclusions about their response. Particular attention is paid to the traditional construction techniques and architectural features that appeared to affect the seismic response of the structures. 
541 In general, poor materials were observed as masonry constituents. Combined with the

542 sparse presence of transversal interlocking stones, a significant portion of URM structures

543 appeared to delaminate and disintegrate easily. On the other hand, timber-reinforced

544 masonry structures showed enhanced seismic performance and structural redundancy,

545 suffering only localized damage while avoiding total collapses.

546 Several local mechanisms were inspected and described, i.e. masonry disintegration, gable

547 end wall overturning, corner mechanism and loss of fireplaces' flues embedded in masonry

548 walls. Proper construction details and structural connections could prevent such

549 mechanisms from occurring.

550 Out-of-plane mechanisms were the most frequent, in most cases resulting in partial or even

551 global collapses. The main factors that determined the appearance of such mechanisms

552 could be summarized to be the following: the unconstrained length, the lack of adequate

553 connections with the transversal walls and the horizontal structural elements, the wall

554 slenderness and the presence of plan irregularities. Considering the above, a good

555 configuration of the quoin stones, the presence of dense transversal walls or an entrance

556 recess, and the existence of timber laces or tie rods could decrease the out-of-plane

557 vulnerability. On the contrary, the "utilization" of a pre-existing side wall to make a semi-

558 detached building, the presence of windows or flues in the proximity of the corners and the

559 lack of a horizontal diaphragm were observed to be detrimental for masonry façades.

560 Structures that experienced a box-like behavior presented in-plane response, in generally

561 preferred as it possess a larger capacity to withstand lateral actions. In-plane damage was

562 observed due to weak spandrels and piers, or overweight structures due to RC slabs.

563 Three types of combined in-plane and out-of-plane mechanisms were also reported, scarcely 564 studied in literature. The first two refer to the interaction of in-plane and out-of-plane 565 actions at the corners or recesses of the structure; with the distinguished feature being the 566 presence or absence of constrain at the top. In addition, partial out-of-plane collapses of in567 plane damaged walls were also observed.

568 A number of collapses of non-structural elements were also inspected i.e. unconnected 569 posts and lintels, chimney tops, roof tiles, pillars, retaining walls and veneer walls. The 570 collapse of such elements might not affect the global structural stability, yet they could 571 result to important monetary loss and even human fatalities.

572 Finally, an insight of the performance of previous interventions is attempted. Concerning 573 techniques intended to improve the structural behavior; firstly a strengthening prioritization 574 is established, and then some representative non-conforming cases are reported. This way, 575 it is clearly shown that the application of several techniques could be detrimental instead of 576 beneficial if basic conditions are not met. Concerning interventions that are materialized for 577 functional purposes, a number of cases is reported that indicate crucial structural aspects 578 arising. Thus, the importance of engineered and well-conceived alterations in existing 579 buildings is stressed. 
580

581

582

583

584

585

586

587

588

589

590

591

592

593

594

595

596

597

598

599

600

601

602

603

604

605

606

607

608

609

610

611

612

613

614

615

616

617

618

619

620

621

\section{Acknowledgements}

This work was partly funded by project STAND4HERITAGE that has received funding from the European Research Council (ERC) under the European Union's Horizon 2020 research and innovation programme (Grant agreement No. 833123), as an Advanced Grant.

The authors would like to thank Maria Kleanthi, Director of the Earthquake Rehabilitation Organization in Greece, for the assistance in the field reconnaissance campaign; and Dr. Vasilios G. Bardakis, President of the Greek Association of Civil Engineers, for the support in writing the first draft.

\section{References}

[1] P. Papadimitriou, I. Kassaras, G. Kaviris, G.A. Tselentis, N. Voulgaris, E. Lekkas, G. Chouliaras, C. Evangelidis, K. Pavlou, V. Kapetanidis, A. Karakonstantis, D. Kazantzidou-Firtinidou, I. Fountoulakis, C. Millas, I. Spingos, T. Aspiotis, A. Moumoulidou, E. Skourtsos, V. Antoniou, E. Andreadakis, S. Mavroulis, M. Kleanthi, The 12 th June $2017 \mathrm{M} \mathrm{w}=6.3$ Lesvos earthquake from detailed seismological $\begin{array}{lllll}\text { observations, J. } & \text { Geodyn. } & 115 & \text { (2018) }\end{array}$ https://doi.org/10.1016/j.jog.2018.01.009.

[2] National Observatory of Athens, Online ShakeMap Service, Website. (2018). https://shake.gein.noa.gr/sm/noa2017lkye/products.html (accessed March 16, 2020).

[3] C. Papaioannou, C. Karakostas, M. Rovithis, T. Salonikios, N. Theodoulidis, K. Makra, V. Lekidis, V. Margaris, K. Morfidis, S. Zacharopoulos, the June-July, 2017 Earthquake Sequences in Eastern Aegean Sea : Ground Motions, Geotechnical Ground Failures and Structural Response, in: 16th Eur. Conf. Earthq. Eng., Thessaloniki, Greece, 2018.

[4] P. Papadimitriou, G.A. Tselentis, N. Voulgaris, V. Kouskouna, E. Lagios, I. Kassaras, G. Kaviris, K. Pavlou, V. Sakkas, A. Moumoulidou, A. Karakonstantis, V. Kapetanidis, G. Sakkas, D. Kazantzidou, T. Aspiotis, I. Fountoulakis, C. Millas, I. Spingos, E. Lekkas, V. Antoniou, S. Mavroulis, E. Skourtsos, E. Andreadakis, Preliminary report on the Lesvos 12 June $2017 \quad M w=6.3$ earthquake, (2017). https://www.emsccsem.org/Files/news/Earthquakes_reports/lesvos_report_nkua_v5.pdf.

[5] A. Kiratzi, The 12 June 2017 Mw 6.3 Lesvos Island (Aegean Sea) earthquake: Slip model and directivity estimated with finite-fault inversion, Tectonophysics. 724-725 (2018) 1-10. https://doi.org/10.1016/j.tecto.2018.01.003.

[6] N. Vavlas, A. Kiratzi, V. Margaris, G. Karakaisis, Probabilistic Seismic Hazard Assessment (PSHA) for Lesvos island using the Logic Tree Approach, Bull. Geol. Soc. Greece. 55 (2019) 109-136. https://doi.org/10.12681/bgsg.20705.

[7] K. Chousianitis, A.O. Konca, Coseismic Slip Distribution of the 12 June $2017 \mathrm{Mw}=6.3$ Lesvos Earthquake and Imparted Static Stress Changes to the Neighboring Crust, J. Geophys. Res. Solid Earth. $123 \quad$ (2018) 8926-8936. https://doi.org/10.1029/2018JB015950.

[8] A. Vött, Relative sea level changes and regional tectonic evolution of seven coastal areas in NW Greece since the mid-Holocene, Quat. Sci. Rev. 26 (2007) 894-919. https://doi.org/10.1016/j.quascirev.2007.01.004. 
[9] E. Lekkas, N. Voulgaris, P. Karydis, G.A. Tselentis, E. Skourtsos, V. Antoniou, E. Andreadakis, S. Mavroulis, N. Spirou, F. Speis, P. Papadimitriou, V. Kouskouna, G. Kassaras, G. Kaviris, K. Pavlou, V. Sakkas, G. Chouliaras, Lesvos Earthquake Mw 6.3, June 12, 2017. Preliminary report., Athens, 2017.

[10] G. Grünthal, R.M.W. Musson, J. Schwartz, M. Stucchi, European Macroseismic Scale 1998 (EMS-98), European Seismological Commission, Luxembourg, 1998. http://lib.riskreductionafrica.org/bitstream/handle/123456789/1193/1281.European Macroseismic Scale 1998.pdf?sequence=1.

[11] A. Annunziato, G.A. Papadopoulos, A. Yalciner, O. Necmioglu, C. Ozer Sozdinler, A. Agalos, M. Charalampakis, G.G. Dogan, M. Kleanthi, T. Novikova, P. Probst, C. Proietti, I. Triantafyllou, Analysis of the Tsunami Event caused by the Mw 6 . 3 Lesvos Island (East Aegean Sea) Earthquake of 12th June 2017, 2017. https://www.emsccsem.org/Doc/Additional_Earthquake_Report/597714/Analysis of the Tsunami Event caused by the Mw 6.3 Plomari Earthquake of 12 June 2017. v2.1.pdf\%0D.

[12] S. Mavroulis, E. Andreadakis, N.I. Spyrou, V. Antoniou, E. Skourtsos, P. Papadimitriou, I. Kasssaras, G. Kaviris, G.A. Tselentis, N. Voulgaris, P. Carydis, E. Lekkas, UAV and GIS based rapid earthquake-induced building damage assessment and methodology for EMS-98 isoseismal map drawing: The June 12, 2017 Mw 6.3 Lesvos (Northeastern Aegean, Greece) earthquake, Int. J. Disaster Risk Reduct. 37 (2019) 101169. https://doi.org/10.1016/j.ijdrr.2019.101169.

[13] N. Chatzis, C. Kkallas, C. Papazachos, M. Anthymidis, E. Rovithis, C. Karakostas, C. Papaioannou, Stochastic Simulation of Seismic Motion and Site-Effects Studies of Ambient Noise and Seismic Data : The Case of the Vrisa Settlement and the $2017 \mathrm{M}=$ 6 . 3 Lesvos Earthquake, (2019) 24-25. https://doi.org/10.1029/2009GL038863.Motazedian.

[14] J. Hecht, Geological map of Greece,1:50.000. Plomari-Mytilene, Ayia Paraskevi, Mithimna, Polichnitos and Eressos sheets., Inst. Geol. Miner. Explor. Greece. (1972).

[15] M. Bruneau, State-of-the-art report on seismic performance of unreinforced masonry buildings, J. Struct. Eng. (United States). 120 (1994) 230-251. https://doi.org/10.1061/(ASCE)0733-9445(1994)120:1(230).

[16] D. Penazzi, M.R. Valluzzi, G. Cardani, L. Binda, G. Baronio, C. Modena, C., Behaviour of Historic Masonry Buildings in Seismic Areas: Lessons Learned from the UmbriaMarche Earthquake, 12th Int. Brick/Block Mason. Conf. Madrid, Spain. (2000) 217235.

[17] D. Gautam, H. Rodrigues, K.K. Bhetwal, P. Neupane, Y. Sanada, Common structural and construction deficiencies of Nepalese buildings, Innov. Infrastruct. Solut. 1 (2016) 1-18. https://doi.org/10.1007/s41062-016-0001-3.

[18] M. Shakya, C.K. Kawan, Reconnaissance based damage survey of buildings in Kathmandu valley: An aftermath of 7.8Mw, 25 April 2015 Gorkha (Nepal) earthquake, Eng. Fail. Anal. $59 \quad$ (2016) 161-184. https://doi.org/10.1016/j.engfailanal.2015.10.003.

[19] L. Decanini, A. De Sortis, A. Goretti, R. Langenbach, F. Mollaioli, A. Rasulo, Performance of masonry buildings during the 2002 Molise, Italy, earthquake, Earthq. Spectra. 20 (2004) 191-220. https://doi.org/10.1193/1.1765106. 
666 [20] F. Aras, E. Düzci, Seismic Performance of Traditional Stone Masonry Dwellings under Çanakkale Seismic Sequences, J. Perform. Constr. Facil. 32 (2018) 1-11. https://doi.org/10.1061/(ASCE)CF.1943-5509.0001173.

[21] L. Sorrentino, S. Cattari, F. da Porto, G. Magenes, A. Penna, Seismic behaviour of ordinary masonry buildings during the 2016 central Italy earthquakes, Bull. Earthq. Eng. 17 (2019) 5583-5607. https://doi.org/10.1007/s10518-018-0370-4.

[22] M. Javed, A.N. Khan, A. Penna, G. Magenes, Behaviour of Masonry Structures During the Kashmir 2005, in: First Eur. Conf. Earthq. Eng. Seismol., Geneva, 2006.

[23] E. Vintzileou, A. Zagkotsis, C. Repapis, C. Zeris, Seismic behaviour of the historical structural system of the island of Lefkada, Greece, Constr. Build. Mater. 21 (2007) 225-236. https://doi.org/10.1016/j.conbuildmat.2005.04.002.

[24] A. Naseer, A. Naeem Khan, Z. Hussain, Q. Ali, Observed seismic behavior of buildings in Northern Pakistan during the 2005 Kashmir earthquake, Earthq. Spectra. 26 (2010) 425-449. https://doi.org/10.1193/1.3383119.

[25] N. Augenti, F. Parisi, Learning from construction failures due to the 2009 L'Aquila, Italy, earthquake, J. Perform. Constr. Facil. 24 (2010) 536-555. https://doi.org/10.1061/(ASCE)CF.1943-5509.0000122.

[26] M. Indirli, L.A.S. Kouris, A. Formisano, R.P. Borg, F.M. Mazzolani, Seismic damage assessment of unreinforced masonry structures after the Abruzzo 2009 earthquake: The case study of the historical centers of L'Aquila and Castelvecchio Subequo, Int. J. Archit. Herit. 7 (2013) 536-578. https://doi.org/10.1080/15583058.2011.654050.

[27] D. Dizhur, J. Ingham, L. Moon, M. Griffith, A. Schultz, I. Senaldi, G. Magenes, J. Dickie, S. Lissel, J. Centeno, C. Ventura, J. Leite, P. Lourenco, Performance of masonry buildings and churches in the 22 February 2011 Christchurch earthquake, Bull. New Zeal. Soc. Earthq. Eng. 44 (2011) 279-296. https://doi.org/10.5459/bnzsee.44.4.279296.

[28] G.P. Cimellaro, I.P. Christovasilis, A.M. Reinhorn, A. De Stefano, T. Kirova, L'Aquila Earthquake of April 6, 2009 in Italy: Rebuilding a Resilient City To Withstand Multiple Hazards, 2010.

[29] J. Ingham, M. Griffith, Performance of unreinforced masonry buildings during the 2010 darfi eld (Christchurch, NZ) earthquake, Aust. J. Struct. Eng. 11 (2011) 207-224. https://doi.org/10.1080/13287982.2010.11465067.

[30] L. Moon, D. Dizhur, I. Senaldi, H. Derakhshan, M. Griffith, G. Magenes, J. Ingham, The demise of the URM building stock in Christchurch during the 2010-2011 Canterbury earthquake sequence, Earthq. Spectra. 30 (2014) 253-276. https://doi.org/10.1193/022113EQS044M.

[31] I. Senaldi, G. Magenes, J.M. Ingham, Damage Assessment of Unreinforced Stone Masonry Buildings After the 2010-2011 Canterbury Earthquakes, Int. J. Archit. Herit. 9 (2015) 605-627. https://doi.org/10.1080/15583058.2013.840688.

[32] Z. Celep, A. Erken, B. Taskin, A. Ilki, Failures of masonry and concrete buildings during the March 8, 2010 Kovancilar and Palu (Elaziĝ) Earthquakes in Turkey, Eng. Fail. Anal. 18 (2011) 868-889. https://doi.org/10.1016/j.engfailanal.2010.11.001. 
[33] A. Penna, P. Morandi, M. Rota, C.F. Manzini, F. da Porto, G. Magenes, Performance of masonry buildings during the Emilia 2012 earthquake, Bull. Earthq. Eng. 12 (2014) 2255-2273. https://doi.org/10.1007/s10518-013-9496-6.

[34] L. Sorrentino, L. Liberatore, D. Liberatore, R. Masiani, The behaviour of vernacular buildings in the 2012 Emilia earthquakes, Bull. Earthq. Eng. 12 (2014) 2367-2382. https://doi.org/10.1007/s10518-013-9455-2.

[35] E. Sayin, B. Yön, Y. Calayir, M. Karaton, Failures of masonry and adobe buildings during the June 23, 2011 Maden-(Elaziğ) earthquake in Turkey, Eng. Fail. Anal. 34 (2013) 779-791. https://doi.org/10.1016/j.engfailanal.2012.10.016.

[36] D. Dizhur, R.P. Dhakal, J. Bothara, J.M. Ingham, Building typologies and failure modes observed in the 2015 Gorkha (Nepal) earthquake, Bull. New Zeal. Soc. Earthq. Eng. 49 (2016) 211-232. https://doi.org/10.5459/bnzsee.49.2.211-232.

[37] R. Sisti, M. Di Ludovico, A. Borri, A. Prota, Damage assessment and the effectiveness of prevention: the response of ordinary unreinforced masonry buildings in Norcia during the Central Italy 2016-2017 seismic sequence, Bull. Earthq. Eng. 17 (2019) 5609-5629. https://doi.org/10.1007/s10518-018-0448-z.

[38] N. Ambraseys, Earthquakes in the Eastern Mediterranean and the Miffle East, A Multidisciplinary Study of Seismicity up to 1900, Cambridge, 2009.

[39] D. Mirabile Gattia, G. Roselli, O. Alshawa, P. Cinaglia, G. Di Girolami, C. Francola, F. Persia, E. Petrucci, R. Piloni, F. Scognamiglio, L. Sorrentino, S. Zamponi, D. Liberatore, Characterization of historical masonry mortar from sites damaged during the central Italy 2016-2017 seismic sequence: The case study of arquata del Tronto, Ann. Geophys. 62 (2019). https://doi.org/10.4401/ag-8019.

[40] O. AlShawa, D. Liberatore, L. Sorrentino, Dynamic One-Sided Out-Of-Plane Behavior of Unreinforced-Masonry Wall Restrained by Elasto-Plastic Tie-Rods, Int. J. Archit. Herit. 13 (2019) 340-357. https://doi.org/10.1080/15583058.2018.1563226.

[41] E. Vintzileou, Timber-reinforced structures in Greece: 2500 BC-1900 AD, Proc. Inst. Civ. Eng. Struct. Build. 164 (2011) 167-180. https://doi.org/10.1680/stbu.9.00085.

[42] A. Tavares, D. D’Ayala, A. Costa, H. Varum, Construction systems, in: A. Costa, J.M. Guedes, H. Varum (Eds.), Struct. Rehabil. Old Build., Building P, Springer Heidelberg New York Dordrecht London Library, 2014: pp. 1-35. https://doi.org/10.1007/978-3642-39686-1.

[43] N. Ruggieri, G. Tampone, R. Zinno, Historical Earthquake-Resistant Timber Frames in the Mediterranean Area, Springer Heidelberg New York Dordrecht London, 2015. https://doi.org/10.1007/978-3-319-16187-7.

[44] J. Ortega, G. Vasconcelos, H. Rodrigues, M. Correia, P.B. Lourenço, Traditional earthquake resistant techniques for vernacular architecture and local seismic cultures: A literature review, J. Cult. Herit. 27 (2017) 181-196. https://doi.org/10.1016/j.culher.2017.02.015.

[45] N. Karydis, Traditional Earthquake-resistant Construction in the East Aegean Sea: The Case of Eresos and Pergamon [in Greek], in: 3rd Natl. Conf. Earthq. Eng. Eng. Seismol., Athens, 2008. 
[46] R. Langenbach, From "Opus Craticium" to the "Chicago frame": Earthquake-resistant traditional construction, Int. J. Archit. Herit. 1 (2007) 29-59. https://doi.org/10.1080/15583050601125998.

[47] T. Makarios, M. Demosthenous, Seismic response of traditional buildings of Lefkas Island, Greece, Eng. Struct. $28 \quad$ (2006) 264-278. https://doi.org/10.1016/j.engstruct.2005.08.002.

[48] C. Casapulla, A. Maione, Experimental and Analytical Investigation on the Corner Failure in Masonry Buildings: Interaction between Rocking-Sliding and Horizontal Flexure, Int. J. Archit. Herit. 14 (2020) 208-220. https://doi.org/10.1080/15583058.2018.1529206.

[49] L. Giresini, F. Solarino, O. Paganelli, D. V. Oliveira, M. Froli, ONE-SIDED rocking analysis of corner mechanisms in masonry structures: Influence of geometry, energy dissipation, boundary conditions, Soil Dyn. Earthq. Eng. 123 (2019) 357-370. https://doi.org/10.1016/j.soildyn.2019.05.012.

[50] Google, Google Maps, (n.d.). https://www.google.com/maps/@39.0410673,26.2011979,3a,75y,189.01h,95.33t/da ta $=$ !3m6!1e1!3m4!1shyrhi_AjyrUW-hIEyocZIQ!2e0!7i13312!8i6656 (accessed March 22, 2020).

[51] D. Perrone, P.M. Calvi, R. Nascimbene, E.C. Fischer, G. Magliulo, Seismic performance of non-structural elements during the 2016 Central Italy earthquake, Bull. Earthq. Eng. 17 (2019) 5655-5677. https://doi.org/10.1007/s10518-018-0361-5.

[52] L. Binda, A. Saisi, C. Tedeschi, Compatibility of materials used for repair of masonry buildings: research and applications, 2006. https://doi.org/10.1007/978-1-40205077-0_11.

[53] C. Modena, M.R. Valluzzi, F. da Porto, F. Casarin, M. Munari, N. Mazzon, M. Panizza, Assessment and improvement of the seismic safety of historic constructions: research and applications in Italy, in: I Congr. Iberoam. Sobre Construcciones Históricas y Estructuras Mampostería, 2008.

[54] C. Modena, M.R. Valluzzi, F. Da Porto, F. Casarin, Structural aspects of the conservation of historic masonry constructions in seismic areas: Remedial measures and emergency actions, Int. J. Archit. Herit. 5 (2011) 539-558. https://doi.org/10.1080/15583058.2011.569632.

[55] D. Dizhur, N. Ismail, C. Knox, R. Lumantarna, J.M. Ingham, Performance of unreinforced and retrofitted masonry buildings during the 2010 darfield earthquake, Bull. New Zeal. Soc. Earthq. Eng. 43 (2010) 321-339. https://doi.org/10.5459/bnzsee.43.4.321-339.

[56] G. Correia Lopes, R. Vicente, T.M. Ferreira, M. Azenha, Intervened URM buildings with RC elements: typological characterisation and associated challenges, Springer Netherlands, 2019. https://doi.org/10.1007/s10518-019-00651-y. 


\section{Appendix A - Structural Observations on Seismic Motion Directivity}

According to [5], [7] and [1] among others, the rupture of the seismic event propagated unilaterally towards NW, causing a forward directivity of the seismic motion. This section attempts to shed light to the seismic motion directivity through structural observations. Two cases are presented, whose damage and failure pattern can reveal the main seismic component. Inherent uncertainties and limitations exist in this attempt, some of which are pointed out; yet the observations appear profound not to be mentioned.

The first case concerns the elementary school of the Vrissa settlement (Figure A. 1). Figure A. 1 (a)-(b) presents two façades that are facing SW and suffered IP damage. Figure A. 1 (c) illustrates the main façade of the school that faces NW and suffered complete OOP collapse. Moreover, Figure A. 1 (d) depicts the main entrance of the school that faces NW and is composed by two pillars. Both pillars experienced rocking at the height of the side retaining walls; with the one on the right collapsing outwards (towards NW) and the one on the left being displaced of about $5 \mathrm{~cm}$ at this height, towards NW. All the above observations point out a seismic motion directivity towards NW. Nevertheless, let us make some more notes about the building. It is constructed on a hill at the SW of the settlement, with slopes in all the surrounding, except SE. Thus slope movement might affected the severity in some direction. In fact, a local landslide occurred at the NE side and the corresponding façade (not showed herein) collapsed OOP. Nevertheless, all the rest façades and the pillars of the entrance point out the same seismic motion directivity towards NW.

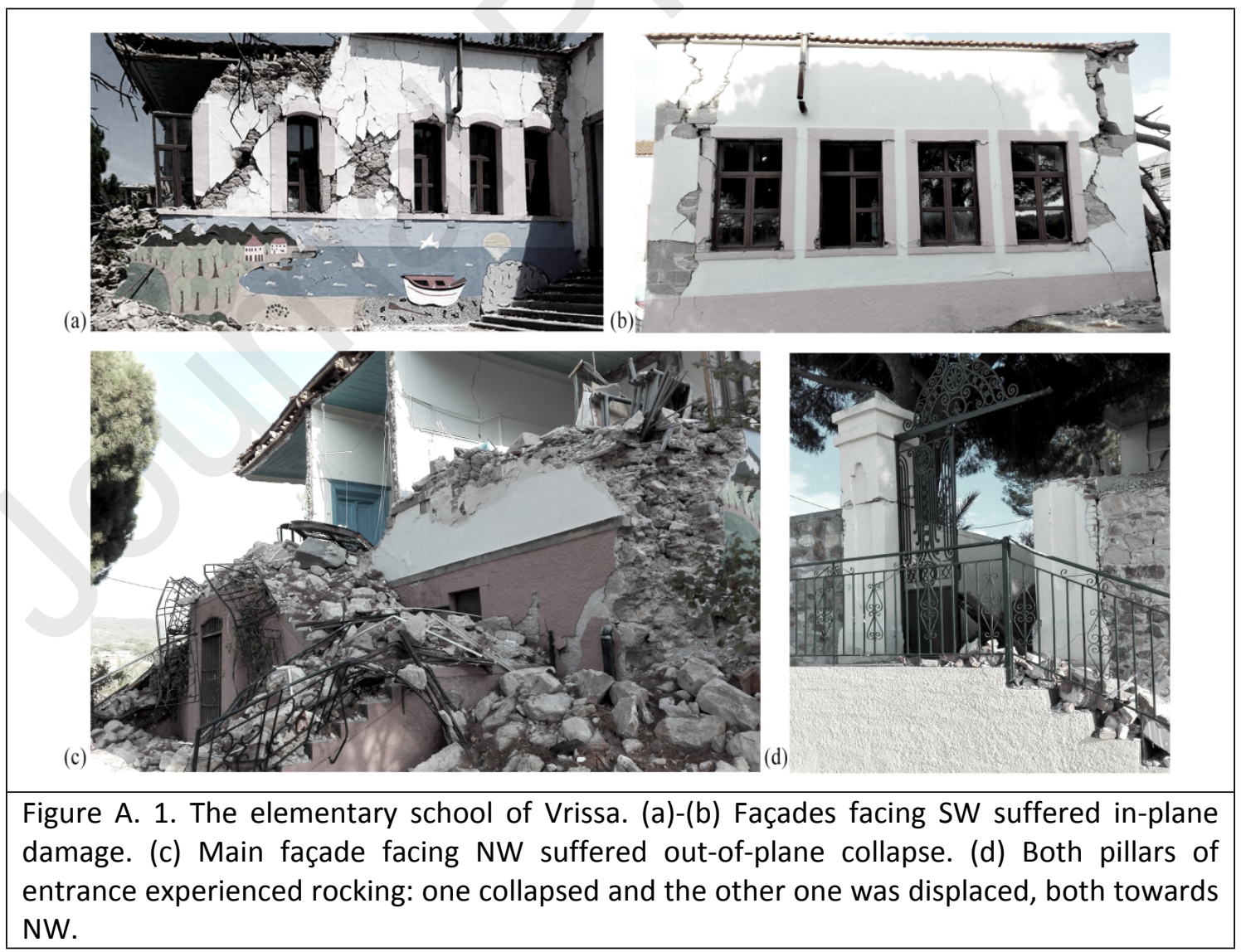


811 Finally, the second case concerns the building presented in Section 4.2 and Figure 28. The 812 observations made there indicate that pounding occurred between the internal RC frame 813 and slab with the external masonry façade. By looking at the damage pattern it is clear that 814 the collision happened at the interface between the slab and the façade that collapsed OOP, 815 while the transversal façades showed only IP damage induced by the previous collision. The 816 façade that collapsed faces SE, while the two transversal façades face SW and NE. Since pounding occurs at large displacements, the aforementioned damage pattern points out that the main seismic component was in the NW-SE direction. 